\title{
OBSERVACIONES SOBRE EL COMPLEJO SOCIAL-LABORAL PORTUARIO RIOPLATENSE DEL SIGLO XVIII
}

\author{
OBSERVATIONS ON THE RIO DE LA PLATA SOCIAL-LABOR \\ COMPLEX OF THE EIGHTEENTH CENTURY
}

María Emilia Sandrín

Universidad Nacional de La Plata Facultad de Humanidades y Ciencias de la Educación Instituto de Investigaciones en Humanidades y Ciencias Sociales https://orcid.org/0000-0001-5921-2735 mariaemiliasandrin@gmail.com

Recibido: marzo 23 de 2019 - Aceptado: mayo 17 de 2019

\section{Resumen:}

En el presente trabajo se propone un abordaje a un sector social del mercado de trabajo portuario regional que vivía de la provisión de bienes y servicios para la navegación del servicio real y para el abasto de las tropas asentadas en el Río de la Plata, o en tránsito hacia otros destinos, en el siglo XVIII. Estudiar a este sector social a través de fuentes fiscales permitió analizar cómo una porción del gasto público en determinados bienes y servicios pudo dinamizar la economía rioplatense y distribuir beneficios entre todos los sectores de la sociedad. Esta perspectiva permitió analizar a las personas que trabajaron en la satisfacción de las demandas y observar si lograron algún grado de prosperidad. Las fuentes para analizar a este sector social son registros contables de determinados acontecimientos testigos dentro del siglo XVIII: libros de Carenas, libros de caja y Balances generales de Proveedores, cartas cuentas de la Caja de Buenos Aires e informaciones relevadas de bibliografía complementaria sobre esta temática en el período especificado.

Palabras-clave: mercado de trabajo portuario regional, sociedad rioplatense, fuentes fiscales, siglo XVIII.

\footnotetext{
Abstract:

This paper aims to show how fiscal sources allowed to approach a social sector of the regional port labor market that lived from the provision of goods and services for the
} 
navigation of the real service and for the supply of the troops settled in the Rio de la Plata Silver, or in transit to other destinations, in the eighteenth century. Studying this social sector through fiscal sources allowed us to analyze how a portion of public expenditure on certain goods and services could boost the economy of Rio de Janeiro and distribute benefits among all sectors of society. This perspective allowed to analyze the people who worked in the satisfaction of the demands and to see if they obtained some degree of prosperity. The sources for analyzing this social sector are accounting records of certain witness events within the eighteenth century: Carenas books, cash books and Suppliers' Balance Sheets, letters from the Caja de Buenos Aires and information from complementary bibliography on this subject in the specified period.

Keywords: society rioplatense, tax sources, eighteenth century

\section{Introducción}

En el espacio rioplatense del siglo $\mathrm{XVIII}^{1}$ se pudieron visualizar las características principales de los centros urbanos latinoamericanos que definieron Socolow \& Hoberman; ya que era el escenario vital del intercambio social y económico, del movimiento y de los conflictos ${ }^{2}$. Era en la ciudad donde los diferentes grupos étnicos, ocupacionales y sociales se encontraban, se influían mutuamente y se fundían. Era el ámbito donde los individuos y los grupos interactuaban, a veces en armonía y otras en conflicto, al tiempo que se afirmaba y erosionaba al mismo tiempo el orden social jerárquico.

En el Río de la Plata, ese orden -en el que la desigualdad de riqueza y estatus se daban por sentadas- surgió de una sociedad de tardía formación con respecto a otras sociedades hispano-criollas, cuyas relaciones con las sociedades indígenas escapaban al modelo emergente de las áreas centrales de la colonización y donde el impacto del aporte africano también revistió notas particulares con respecto a otros espacios americanos. Esta sociedad era una formación de carácter variable, donde los individuos estaban relacionados unos con otros por un modo específico de dependencias recíprocas y cuya reproducción suponía un equilibrio móvil de tensiones. ${ }^{3}$ Allí, la libertad de cada individuo estaba inscripta en una cadena de interdependencias, en donde eran esenciales las redes de dependencia recíprocas que hacían que cada acción individual se interrelacionada con toda una serie de otras al modificar, a su vez, la figura misma

\footnotetext{
${ }^{1}$ Fernando Jumar, "La región Río de la Plata y su complejo portuario durante el Antiguo Régimen”, en Raúl Fradkin (dir.), Historia de la Provincia de Buenos Aires, Tomo II, Buenos Aires, Universidad Pedagógica de la Provincia de Buenos Aires, EDHASA, 2012, pp. 123-158.

2 Louisa Hoberman \& Susan Socolow (comps.), Ciudades y sociedad en Latinoamérica colonial, Buenos Aires, Fondo de Cultura Económica, 1992.

3 Norbert Elias, ¿Qu'est-ce que la sociologie?, París, L’Aube, 1991.
} 
del juego social. Como toda sociedad, también la rioplatense era un punto de contacto, de interrelación, de confluencia de circuitos y redes; en la que la movilidad variable de cada una de las cadenas de interdependencia fue definiendo el carácter específico de la compleja configuración social rioplatense.

El espacio rioplatense controlaba y articulaba la capacidad de movilización de recursos tanto humanos como naturales de su entorno. Todo el conjunto variado de redes de sociabilidad y de poder, de intercambio tanto material como simbólico, fue permitiendo la especialización de parte de la población en diversas funciones. Funciones mercantiles, intercambiando bienes y servicios; productivas, proveyendo productos; políticas, administrando, controlando su entorno; militares, formando parte de las fuerzas, aprovisionando tropas estables o en tránsito; entre otras funciones.

La economía de la región Río de la Plata estaba dinamizada por: a) la navegación privada comercial; b) el comercio interior por tierra y por agua dulce (no por la actividad de intercambio en sí, sino por todo lo que debe ponerse en movimiento para que se dé la concreción del hecho mercantil); c) las demandas de la Corona de bienes y/o servicios necesarios para proveer las tripulaciones de la navegación ultramarina, como para las tropas asentadas en la región o en tránsito hacia otros destinos. Estas demandas podían presentarse en forma aislada, de a un grupo por vez, alternarse entre barcos y/o tropas, o generarse ambas en simultáneo. ${ }^{4}$

\footnotetext{
4 Para ampliar el tema ver: Fernando Jumar et al, "El comercio ultramarino y la economía local en el complejo portuario rioplatense. Siglo XVIII”, en Anuario del IEHS, 21, 2006, pp. 235-254. Fernando Jumar, Le commerce atlantique au Río de la Plata, 1680-1778, 2da. ed. Aumentada, $1^{\text {a }}$ ed. Electrónica, La Plata, UNLP, 2010, http://www.memoria.fahce.unlp.edu.ar/tesis/te.364/te.364.pdf (consulta 10/02/2019). Fernando Jumar \& Nicolás Biangardi, "La conjunción entre espacio económico y territorialidad. Río de la Plata. Siglo XVIII", en Richard Jorba \& Marta Bonaudo (coords.), Investigaciones regionales. Enfoques para la Historia, Siglos XVIII-XX, La Plata (Argentina), FaHCE-UNLP, 2014, pp. 75-91. Fernando Jumar, "El comercio ultramarino por el complejo portuario rioplatense y la economía regional, 17141778", en Magallánica, Revista de Historia Moderna, Vol. 3, (5), 2016, pp. 166-259. María Emilia Sandrín, "El abasto y la provisión de bienes y servicios en el complejo portuario rioplatense. Siglo XVIII”, en Silvia Mallo \& Beatriz Moreyra (coord.), Miradas sobre la historia social en la Argentina en los comienzos del siglo XXI, Córdoba, Centro de Estudios Históricos, Prof. S. A, Segreti, La Plata, Centro de Estudios de Historia Americana Colonial, 2008, pp. 573-585. M. Sandrín, Bizcocheras, lancheros y demás... Los estímulos económicos de la guerra para los sectores medios y bajos del complejo portuario rioplatense. 1735-1737, Saarbrücken, Editorial Académica Española, 2011. M. Sandrín, “¿Quién amasa la masa? Los proveedores de comestibles en el sitio a Colonia del Sacramento de 1735-1737", en Andes, 24, 1, 2013, http://www.scielo.org.ar/scielo.php?script=sci_arttext\&pid=S1668-80902013000100008\&lng=es\&tlng=es. (consulta 5/03/2019). M. Sandrín, "La actividad económica de los asentistas de víveres de la Marina de Montevideo, 1770-1810", en América Latina en la Historia Económica, vol. 21, n. 1, 2014a, pp. 92-114. http://www.scielo.org.mx/ scielo.php?script=sci_arttext\&pid=S1405-22532014000100004\&lng=es\&tlng=es (consulta 5/O3/2019). M. Sandrín, "Los carpinteros, calafates, herreros, faroleros y demás trabajadores de las Fragatas-correo en Montevideo y su posible participación en el proceso emancipador”, en Naveg@mérica, Revista electrónica editada por la Asociación Española de Americanistas, 12, 2014b, http://revistas.um.es/navegamerica. (consulta 5/o3/2019). M. Sandrín, "La región Río de la Plata como articuladora de demandas que dinamizaron su economía en el largo siglo XVIII (1680-1810)", en Trabajos y Comunicaciones, 48, 2018, https://doi.org/10.24215/23468971eo71. (consulta 5/03/2019).
} 
La región Río de la Plata tuvo la capacidad de poder brindar una amplia serie de servicios a la navegación y a las tropas estables y/o en tránsito hacia otros destinos durante el siglo XVIII. Se trata de la provisión de bienes y servicios destinados al mantenimiento de las tripulaciones durante sus viajes de retorno y de las embarcaciones en condiciones de navegar, así como para las tropas asentadas en suelo rioplatense o en tránsito hacia otras tierras. De los diversos análisis que se pueden realizar a partir de estas constataciones, resalto la primera en tanto que reveladora de cómo el mundo de la producción encontró un estímulo más en la navegación ultramarina y las tropas y la segunda, de cómo esa navegación y las tropas generaron una demanda de servicios especializados Ambos estímulos generaron fuentes de trabajo y de prosperidad para diversos actores locales.

En particular, decido acceder a un mayor conocimiento de la sociedad local a través del análisis de los individuos que estaban detrás de la provisión de bienes y servicios para las tripulaciones de la navegación ultramarina y las tropas asentadas en el Río de la Plata o en tránsito hacia otros destinos en el siglo XVIII. Abordar de modo detallado y sistemático cada una de las demandas de barcos y/o tropas a lo largo de todo un siglo era una tarea casi irrealizable. Por ello, establecí como estrategia el análisis de casos-testigo de cada una de las esferas económicas dinamizadas por el gasto público. Para las demandas de las tropas se usó como caso testigo el Sitio a Colonia del Sacramento de 1735-1737 y para el análisis de las demandas de la navegación ultramarina se utilizó las reparaciones llevadas adelante en las Fragatas-Correo para mantenerlas en condiciones marineras entre 1767 y 1802, que sirven para sostener mis hipótesis generales del papel dinamizador de la corona en la sociedad y la economía del espacio rioplatense en el siglo XVIII, generando una variada gama de demandas que debían ser satisfechas por este espacio y su gente. La historiografía nos muestra que, a lo largo de este siglo, la presencia de la corona española en el Río de la Plata no sólo no decayó, sino que se reforzó. Desde la Guerra de la Liga de Augsburgo hasta la crisis del comienzo del siglo XIX, el Río de la Plata estuvo presente en todas las guerras de la monarquía, como teatro de operaciones o como frontera que había que reforzar ante posibles ataques.

Las fuentes usadas -esencialmente económicas- permiten también analizar la sociedad y sus sectores vinculados a la actividad portuaria. Me refiero a los registros contables de determinados acontecimientos-testigo dentro del siglo XVIII: libros de Carenas ${ }^{5}$, libros de caja y Balances generales de Proveedores de barcos y/o tropas ${ }^{6}$, cartas-cuenta

5 Archivo General de la Nación de Argentina (en adelante AGN), AGN, XIII-15-6-2.

6 AGN, IX 4-4-2. 
de la Caja de Buenos Aires ${ }^{7}$, contratos de asientos $^{8}$, cartas y/o notificaciones $^{9}$, testamentarías $^{10}$, recibos individuales firmados por cada persona a la que le pagaron el producto y/o servicio ${ }^{11}$, datos de proveedores de los registros de navíos ${ }^{12}$, informaciones relevadas de bibliografía complementaria sobre esta temática en el período especificado, entre otras fuentes. ${ }^{13}$

Las fuentes fiscales sirvieron no sólo para realizar un análisis económico, sino también para responder a un amplio espectro de preguntas en torno a las estrategias de subsistencia y formas de trabajo de diversos y variados segmentos sociales intentando definirlos, desde su actividad económica y laboral, en sus características y diferencias. Reitero que cuando no siempre pueden rescatarse todos los sectores sociales en las fuentes, estas fuentes fiscales permitieron abordar su estudio desde el análisis del mercado de trabajo portuario regional que vivía de la provisión de bienes y servicios para la navegación del servicio real y para el abasto de las tropas asentadas en el Río de la Plata, o en tránsito hacia otros destinos, en el siglo XVIII.

Estudiar a estos sectores sociales permitió incluso analizar cómo una porción del gasto público en determinados bienes y servicios pudo dinamizar la economía rioplatense y distribuir beneficios entre todos los sectores de la sociedad; pues posibilitó también analizar a las personas que trabajaron en la satisfacción de las demandas y observar si lograron algún grado de prosperidad.

Con respecto al sector social proveedor de bienes y/o servicios, incluidos en lo que denomino complejo social laboral portuario, es decir el conjunto de trabajadores del complejo portuario rioplatense, se pensó en función de los actores involucrados dando

\footnotetext{
7 AGN, XIII-14-1-3.

8 Archivo General de la Nación de Uruguay, (en adelante AGNU), ex Archivo y Museo Histórico (en adelante AMH), caja 174, 236, 240, 241-carpeta 27, 245-carpeta 31, 256-carpeta 39 y caja 267-carpeta 50. AGNU. Protocolos de Marina 1805-1808 y Registro de Protocolizaciones 1803 a 1809, folios 39 a 47. AGNU. Protocolos de Marina. Fianza de buques. 1803-1804, folios 79 a 81, 103 a 117.

9 AGNU, Archivos Particulares (en adelante AP), caja No 105, carpeta 7; caja 106. AGNU, ex Archivo General Administrativo (en adelante AGA), Libros de la Administración Central, caja 215.

${ }^{10}$ AGNU, Archivo Judicial. Protocolos de la Escribanía Pública. Año 1791, tomo 1. AGNU. Escribanía de Gobierno y Hacienda (en adelante EGH). Protocolos. Libro 5773, expediente 117, legajo 21. AGNU. EGH, caja 36, 74 y 79, expediente 140.

${ }^{11}$ AGN, IX 4-4-2; IX 4-4-3 y IX 4-4-4.

${ }^{12}$ AGN, IX 43-1-4 leg. 7, exp. 3; IX 43-1-5, leg. 8, exp. 3; IX 43-1-6, leg. 9, exp. 2; IX 43-1-10, leg. 13, exp. 2. AGN, IX 432-4, leg. 17, exp. 3; IX 43-3-7, leg. 31, exp. 1; AGN, IX 43-3-8, leg. 32; IX 43-4-2, exp. 1.

${ }_{13}$ Para observar la metodología usada en el análisis de las fuentes mencionadas ver M. Sandrín, Bizcocheras, lancheros y demás. M. Sandrín, "Regíon Río de la Plata”. María Emilia Sandrín, "Las fuentes fiscales para abordar el complejo social-laboral portuario rioplatense: los libros de carenas. 1767-1802”, en Revista Electrónica de Fuentes y Archivos "Prof. Carlos S. A. Segreti", 8, 2017, pp. 156-174. http://www.refa.org.ar/file.php?tipo=Contenido\&id=177 (consulta 5/03/2019).
} 
respuestas a diversas preguntas: ¿Eran proveedores especializados en un solo bien y/o servicio, o iban rotando sus provisiones?; ¿cuál era la periodicidad de sus abastecimientos?; ¿eran proveedores directos o eran “intermediarios" entre éstos y los destinatarios de los bienes y/o servicios?; ¿qué incidencia económica tuvieron sus provisiones dentro de los gastos totales del acontecimiento testigo estudiado?

La demanda de bienes puede dividirse en dos grandes grupos. Los comestibles (principalmente los establecidos en la ración diaria reglamentaria, algunos con una importante y compleja cadena productiva) ${ }^{14}$ y los no comestibles (utensilios e insumos para los determinados “oficios portuarios" necesarios para el mantenimiento de las embarcaciones en condiciones marineras y para satisfacer los requerimientos de las tropas estables o en tránsito) ${ }^{15}$.

Entre los servicios demandados se encuentran determinados oficios: calafates, estibadores/arrumadores, herreros, carpinteros, faroleros, caldereros, latoneros, estañadores, toneleros, armeros, aserradores, albañiles, silleros, zapateros, pintores, buzos, ingenieros, cocedores de brea, peones, entre otros; relacionados a la logística necesaria para un conflicto bélico o para mantener a una embarcación en "condiciones marineras": fletes de lancha, carreteros, carretilleros, chasquis, mandaderos, entre otros.

Las demandas de bienes y/o servicios por parte de barcos y tropas fueron constantes a lo largo del período, tanto por el creciente número de embarcaciones la circulación ultramarina, como de expediciones en defensa de los territorios americanos. ${ }^{16}$

La evidencia de la necesidad de revisar el sistema defensivo de los territorios americanos obligó a intensificar el envío de tropas y suministros militares a América y a abordar importantes reformas en las fortificaciones y estructuras militares ${ }^{17}$. En el Río de la Plata la

\footnotetext{
${ }^{14}$ Bizcocho, vino, tocino, miniestra de garbanzos o arroz, sal, carne salada, aceite, vinagre, queso. También se evidenciaron demandas de ajos, cebollas, tomates, jamones, lechugas, jamones, pasas de uva e higo, repollos, perdices, huevos, entre otros comestibles.

${ }^{15}$ Barriles, botijas, ollas, armas, hachas, martillos, calderos, faroles, vestimenta, telas, maderas, piedras, hierro, cobre, clavos, cueros, hilos, leña, entre tantos otros.

${ }^{16}$ Para un análisis de las demandas que dinamizaron la economía rioplatense en el largo siglo XVIII ver María Emilia Sandrín, La demanda de bienes y servicios para la Corona y la navegación ultramarina en el complejo portuario rioplatense y la dinamización de la economía regional. 1680-1810. Tesis de posgrado, Doctorado en Historia, Universidad Nacional de La Plata, Facultad de Humanidades y Ciencias de la Educación, 2016. http://www.memoria.fahce.unlp. edu.ar/tesis/te.1217/te.1217.pdf (consulta 5/03/2019) M. Sandrín, "Región Río de La Plata".

${ }^{17}$ Rafael Torres Sánchez, "Tejiendo una hacienda imperial: unir los manejos de la Real Hacienda de España y América en el reinado de Carlos III”, en Michel Bertrand \& Zacarías Moutoukias (eds.), Changement institutionnel et fiscalité dans le monde hispanique (1750-1850), Toulouse, Université de Toulouse, 2014.
} 
guerra era algo natural que había que afrontar, la guerra era la normalidad. Sobre el telón de fondo provisto por la mayor o menor virulencia del enfrentamiento con los pueblos originarios que no lograron ser sometidos, la condición de frontera de la Monarquía española incluyó al Río de la Plata desde temprano en los conflictos entre los europeos por el control del continente y sus puertas de acceso a las riquezas que escondía o podía generar. Continuamente había conflictos bélicos, para todos se tomaron previsiones locales, aunque no en todos los casos el Río de la Plata se convirtió en teatro de la guerra. Ello se tradujo en obras y la llegada de expediciones militares que requerían tanto bienes como servicios de los sectores productores/proveedores especializados en abastecerlos, provocando una dinamización de la economía rioplatense, tanto para cubrir las demandas de los ejércitos, como las de la marina (además de abastecer a todas las embarcaciones de la navegación ultramarina comercial).

Si bien tanto el complejo productivo agropecuario como el área de servicios de la región rioplatense fueron altamente movilizados por las demandas de la navegación y de las tropas, generando una importante dinamización económica local, también resultaron estimuladas otras economías regionales americanas a través de la provisión de insumos necesarios que no se encontraban en la región. Con ello, el Río de la Plata se fue convirtiendo en una fuente de estímulo para producciones regionales que encontraron allí mercado.

Como este es un texto de síntesis de trabajos anteriores, se remite a ellos cada apartado para una mejor comprensión del tema.

\section{Los asentistas, actores claves de la sociedad rioplatense ${ }^{18}$}

Los asentistas de Marina fueron uno más de los tantos actores económico-sociales en el espacio rioplatense destinados a la satisfacción de las demandas que el complejo portuario local exigía como zona portuaria.

De todos los asientos, el de la provisión de víveres fue el más importante. Su función era aportar las raciones con que se mantenían las tripulaciones y guarniciones de la Armada real en el Río de la Plata o en tránsito hacia otros destinos; baste como ejemplo que la provisión de víveres en una contienda militar podía insumir más de 50\% de los

\footnotetext{
${ }^{18}$ Este aparte resume lo analizado en trabajos anteriores sobre los asentistas donde se usó una batería de fuentes tales como contratos de asientos, cartas y/o notificaciones, testamentarías. Para un análisis detallado de estas fuentes, los asentistas, sus estrategias de negociación y demás ver M. Sandrín, "Actividad económica de los asentistas".
} 
gastos totales de ese conflicto. ${ }^{19}$

La cantidad de bienes incluidos, las complejas cadenas de producción y comercialización involucradas para que lleguen a sus consumidores, la relación que había que tener con el entramado institucional para alcanzar los contratos, convierte a estos actores en un excelente mirador para abordar diversas problemáticas relacionadas con la historia económico-social del Río de la Plata. Ellos tenían un papel preponderante en la concreción efectiva de la dinamización que la circulación ultramarina y la Corona generaban para la economía regional.

Por ejemplo, para proveer el bizcocho (principal alimento de la dieta tanto de marinos como de soldados), entran en juego análisis de la producción agraria con los procesos de producción, empaque y distribución. El aprovisionamiento del bizcocho también permitió ver la presencia de autoridades preocupadas por la calidad de la prestación de los servicios por los que pagaba, lo que sin duda traducía un interés por el bienestar de marineros y soldados. ${ }^{20}$ Así aparece la dimensión institucional de este rubro. En la obtención y/o renovación de los contratos entraban en juego todos los elementos típicos de la monarquía española, favores, contra-favores y un éxito de los actores en sus objetivos derivados de su inserción en las redes de relaciones que hacían funcionar a la monarquía.

El estímulo a la producción regional se observa en la estructura productiva que debían tener los asentistas para poder en muy tiempo cumplir con la satisfacción del importante número de raciones solicitado. Hubo individuos que tuvieron establecimientos propios para proveerse por su cuenta de los víveres necesarios para la ración diaria reglamentaria, o al menos con buena cantidad de los víveres presentes en ellas; pero al mismo tiempo cuando estos establecimientos no fueron suficientes para afrontar las exigencias de aprovisionamiento, los asentistas supieron contar con una densa red de proveedores para abastecerse de aquello que no podían producir. ${ }^{21} \mathrm{~A}$ pesar de que no estaba formalmente permitido el establecimiento de subcontratos, el importante volumen del bizcocho hizo

${ }^{19}$ Es el caso del Sitio a Colonia del Sacramento de 1735-1737, donde la provisión de comestibles acaparó 53,84\% del gasto total de la contienda. Ver M Sandrín, "Demanda de bienes y servicios".

${ }^{20}$ AGNU, ex AMH, caja 236, folio 4, cláusula 10. AGNU, caja 240, folio 1 vuelta, cláusula 7.

${ }^{21}$ Esto se pudo apreciar en el caso de Battle u Carreó cuando Magariños le transfiere el asiento de víveres para la Marina en 1806, le vende también la casa de panadería y quinta La Aguada, establecimiento desde donde salían buena parte de los vivieres necesarios para la ración diaria de los integrantes de esta fuerza. AGNU. Protocolos de Marina 1805-1808 y Registro de Protocolizaciones 1803 a 1809, folios 43 y 44. Para la tasación véase AGNU, ex AMH, caja 174. Para la escritura, véase AGNU, AP, caja 106, f. 19 vuelta. 
que en la práctica buena parte fuera provista de esa manera. ${ }^{22} \mathrm{Al}$ considerar las enormes cantidades que cada asentista debía abastecer y el trabajo que la cadena productiva y de comercialización del mismo generaba, resulta lógico que se haya subcontratado el rubro dado que había que producir grandes cantidades en poco tiempo. Con estas prácticas de subcontratos se establecían a su vez diversas jerarquías de asentistas, ya que estos subcontratistas, integrarían una segunda línea de abastecimiento. ${ }^{23}$

Los asentistas de víveres, dado los grandes volúmenes de trigo que se necesitaban para hacer los panificados de los cinco años que duraba su contrato, se convertían en acopiadores de trigo, llegando en casos de escasez de granos a ser los únicos que contabancon el cereal. Un ejemplo de ello es cuando ni siquiera los panaderos tenían para poder hacer el pan necesario para Semana Santa y el Cabildo recurre al asentista Vázquez para solicitarle un préstamo de trigo. ${ }^{24}$ También se pudo seguir comprobando la importancia económica y política que tenía el negocio del aprovisionamiento de bizcocho pues en Montevideo durante el período virreinal, al igual que en Buenos Aires en épocas anteriores, el Cabildo recurrentemente prohibía abrir panaderías, para asegurar el negocio y la ganancia de estos asentistas y su red armada de provisión. ${ }^{25}$

Algunos asentistas armaron también su propia red de transporte para asegurarse el traslado de los víveres y demás géneros desde su lugar de producción, recolección o

\footnotetext{
${ }^{22}$ Hay que recordar que los asentistas siempre debían tener listas 20.000 raciones ordinarias. No se han encontrado quejas por desabastecimiento, reclamos o motines por hambre de las embarcaciones de la Armada. Tampoco se han hallado casos declarados de tripulación muerta en altamar por hambre. Hay que pensar que con el abastecimiento de estas raciones se está jugando la supervivencia de estas personas en el mar (un viaje a España por ejemplo duraba un promedio de 120 días) y que buena parte de la economía del Río de la Plata colonial giraba en torno al éxito del viaje de estos barcos. Seguramente algún fraude en la cantidad y la calidad hubo, pero no en cifras descomunales, pues cuando los hubo (al menos en lo concerniente a calidad) fueron denunciados. AGNU, ex AMH, caja 236, folio 2.

${ }^{23}$ Un ejemplo de subcontrato es el caso de Miguel de Zamora, quien en cuatro años del quinquenio de 1790-1795 suministró el pan por contrata particular con el asentista Manuel Vázquez, no obstante, la falta de granos y el crecido precio que tuvo que pagar durante tres años. AGNU, ex AHM, caja No 241.

${ }^{24}$ AGNU, ex Archivo General Administrativo (en adelante AGA), Libros de la Administración Central, caja 215.

${ }^{25}$ Es el caso de Manuel Ximenez y Gomez, un asentista de víveres de Montevideo para los años 1812 y 1813 , quien a comienzos del año 1805 había arrendado la casa de panadería y atahonas de don Miguel Zamora en Montevideo, pero el Cabildo reiteradamente le prohibía abrirla. Era tal su desazón que abre una instancia judicial para que se agilicen y esclarezcan las razones por las que reiteradamente se le impide abrir esta casa panadería. Ver AGNU. EGH, caja 79, expediente 140. Si bien para una época anterior en el tiempo, un buen ejemplo de esta "regulación" es el lanchero Francisco Rodríguez un transportista que en el sitio de Sacramento de 1735-1737 realizó innumerables viajes con sus lanchas cargadas de bizcocho entre Buenos Aires y Montevideo, quien en la reunión del Cabildo del 30 de septiembre de 1738 ofrece dar el bizcocho que necesitasen las fragatas y la gente del sitio, pero no lo deja y le responde que gracias a la elaboración del bizcocho se mantenían en Buenos Aires muchos de los vecinos y viudas pobres cargados de familia. AGN, Acuerdos del extinguido Cabildo de Buenos Aires, serie III, t. XI, 1933, pp.501 y 502. Estos dos ejemplos muestran que el negocio de los bizcochos no sería tan poco rentable o mal negocio para aquel que quisiera emprenderlo. Otro dato significativo es que tanto Ximenez y Gomez como Rodríguez, conocían, por sus funciones (asentista de víveres y lanchero) las enormes cantidades de bizcocho que se producían y circulaban por ambas orillas del Río de la Plata.
} 
compra, hasta el muelle. ${ }^{26}$

Vínculos y contactos con las autoridades e instituciones implicadas en las decisiones destinadas a los contratos de asientos o a los abastecimientos en sí, permitieron a varios asentistas sacar ventajas en sus negocios, acaparar determinado rubro del abasto o conseguir préstamos para sus empresas. Para muchos, haber ganado los diversos contratos les sirvió para acceder a una infinidad de negocios y de ganancias. La mayoría de los "grandes asentistas" desarrollaron multiplicidad de negocios, muchos relacionados entre sí: asentistas, comerciantes, saladeristas, navieros, prestamistas, armadores de embarcaciones corsarias; y los llevaron delante de manera exitosa ${ }^{27}$; salvo Batlle y Carreó a quien la coyuntura política y económica del momento en que actúa le perjudica y termina en la ruina.

Los asentistas montevideanos pudieron maximizar beneficios extendiendo sus abastecimientos a otros rubros además de la Marina pues hubo quienes más allá de proveer la Armada Real abastecieron los buques correos y se dedicaron a proveer de víveres y demás pertrechos a las tropas presentes en el Río de la Plata en el momento de validez de su contrato. ${ }^{28}$ Este abastecimiento de dos demandas diferentes: tripulación de la navegación ultramarina y tropas por una misma persona, también fue observado en la primera mitad del siglo XVIII, aunque de distinta manera. En esa oportunidad el mismo proveedor abastecía del mismo bien y servicio a las tropas del Sitio a Colonia del Sacramento de 1735-1737 cuando por el conflicto bélico no salía ningún barco, es decir, cuando una demanda caía. En el caso del asentista montevideano, abastece ambas demandas contemporáneas.

A través de sus contratos, redes y volúmenes de bienes provistos, los asentistas permiten entrar al mundo de la producción de bienes y/o servicios y percibir, aunque de modo difuso, los sectores sociales ajenos a la elite.

\footnotetext{
${ }^{26}$ AGNU, EGH, Protocolos, Libro 5773, expediente 117, legajo 21, folio 5 .

${ }^{27}$ Por ejemplo, Francisco Antonio Maciel, además de la enorme cantidad de empresas que cumplía (fue naviero, saladerista, procesador de sebo, traficante de esclavos, asentista, hacendado, importador y exportador), también monopolizó para la misma época el abasto de velas para el presidio y los cuarteles, guardias y destacamentos de Montevideo y su jurisdicción; coronando de esa manera un negocio por demás prometedor.

${ }^{28}$ Es el caso de Magariños quien abasteció a las tropas presentes en el Río de la Plata en el momento de validez de su contrato, a tropas de blandengues, a voluntarios de caballería de Córdoba, a tropas auxiliares de Liniers, entre otras. AGNU, AP, caja No 105, carpeta 7, folios 5 a 7 .
} 


\section{Los proveedores del Sitio a Colonia del Sacramento de $1735-1737^{29}$}

El sitio a Colonia del Sacramento debe incluirse dentro de una etapa conflictiva que se suscitó entre las coronas de España y Portugal, entre los años 1680-1777, producto de la instalación intermitente de los portugueses desde el año 1680 en las tierras pretendidamente españolas de la banda norte del río de la Plata.

Analizar las actividades económicas realizadas por los proveedores del sitio a Colonia del Sacramento permite establecer la conexión entre la estructura económica de una sociedad en expansión y las prácticas económicas desplegadas por un determinado sector social para sobrevivir. Las fuentes trabajadas para acercarse a los gastos totales y parciales del sitio de Colonia del Sacramento y a los proveedores de bienes y servicios para las tropas destinadas al mismo, fueron el Libro de Caja ${ }^{30}$ y el Balance General ${ }^{31}$ de Don Juan Antonio de Alquizalete, Proveedor de los gastos hechos en la expedición, y los recibos individuales ${ }^{32}$ firmados por cada persona a la que Alquizalete le pagó el producto o servicio.

Las fuentes permitieron obtener un total general de los gastos ocasionados por el sitio y revelar, mediante el seguimiento de la satisfacción de las diversas demandas, la dinamización que la contienda pudo originar en las distintas esferas económicas: la local, la americana extra regional o la extra americana; a la vez que se pudo registrar cada uno de los aprovisionamientos realizados por cada proveedor involucrado en la satisfacción de las distintas demandas. Una vez que se identificaron cada uno de estos proveedores de

\footnotetext{
${ }^{29}$ Para un análisis detallado del Sitio a Colonia del Sacramento de 1735-1737 ver M. Sandrín, "Bizcocheras, lancheros y demás”. María Emilia Sandrín, "Análisis de las fuentes utilizadas y a utilizar para el estudio económico de los sectores sociales medios y/o bajos en el complejo portuario rioplatense. 1680-1810", en María Emilia Sandrín et al, Temas de Patrimonio cultural 30: Argentina de Puertos III (comp.) por Marcelo Weissel, Buenos Aires, Comisión para la Preservación del Patrimonio Histórico-Cultural, Ministerio de Cultura-Gobierno de la Ciudad Autónoma de Buenos Aires, 2013, pp. 37-56. M. Sandrín, ¿Quién amasa la masa?. M. Sandrín, "La demanda de bienes".

${ }^{30}$ En el citado libro Alquizalete detalla día por día los gastos hechos en la provisión de víveres, servicios, géneros y pertrechos necesarios para la subsistencia de las tropas del sitio de la Colonia del Sacramento, la ciudad de Montevideo, de las baterías de la Ensenada de Barragán y las de las embarcaciones mayores y menores que sirvieron al Rey durante la contienda, además de los pagos a distintos individuos por los gastos extraordinarios ocurridos en ese momento. Figuran los datos de a quién se le pagó el producto y/o el servicio, la fecha de pago, el bien y/o servicio y a cuánto se le pagó, en casos excepcionales se menciona también el lugar de residencia del proveedor. AGN, IX 4-4-2.

${ }^{31}$ En éste, están asentados los bienes que fueron suministrados al Proveedor General, ordenados por producto, brinda la fecha, el proveedor, y la cantidad entregada del mismo; pero resta un dato importantísimo que es el valor pagado por cada uno de ellos, tampoco consta el importe total de los mismos. Una información muy valiosa que sí aporta este Balance, son los datos de cargo y data de los productos; en el cargo figuran a quién Alquizalete le pagó el producto, y en la data a quién se lo entrega para su distribución. AGN, IX 4-4-2.

${ }^{32}$ Estos recibos aportan la mayor cantidad de datos: fecha del pago (en algunos casos la fecha en que se suministró el bien o servicio y la cantidad de días trabajados); nombre del proveedor o de a quién se le están pagando esos víveres, géneros, pertrechos o servicios; producto y cantidad entregado; importe individual (en algunos casos donde se mencionan más de un producto) importe total en todos los recibos. Todas estas informaciones contenidas en esta tercera fuente fueron cruzadas con los datos de las anteriores fuentes. Estos recibos individuales se encuentran desordenados en varios legajos: AGN, IX 4-4-2; IX 4-4-3 y IX 4-4-4.
} 
bienes y servicios, para empezar a reconstruir las redes de relaciones puestas en acción para satisfacer las respectivas demandas, se investigó sobre sus vidas en diccionarios biográficos, censos, padrones, fuentes judiciales, entre otras fuentes.

Para un mejor análisis, se analizó a los proveedores del sitio de Colonia del Sacramento de 1735 a 1737 dividiéndolos en categorías de acuerdo con el producto y/o servicio que proveían. A partir de ello, se pudo establecer que hay proveedores de comestibles, de servicios relacionados con la logística y la gestión del sitio; y de bienes no comestibles y servicios relacionados con el "campamento" de la contienda. Como se observa en el Cuadro 1, se analizó dentro de cada una de estas categorías, qué porcentaje de productos y/o servicios eran dinamizadores de las distintas esferas productivas: local, americana extra regional, y extra americana.

Cuadro 1: Gastos totales del Sitio, divididos por categorías y porcentaje de las esferas económicas que dinamizan

\begin{tabular}{|l|l|l|l|l|l|}
\hline \multicolumn{4}{|c|}{} \\
\multicolumn{1}{|c|}{ Categoría } & $\begin{array}{c}\text { Pesos de 8 } \\
\text { reales }\end{array}$ & $\begin{array}{c}\text { \% del total } \\
\text { general }\end{array}$ & Local & $\begin{array}{c}\text { Americana } \\
\text { extra } \\
\text { regional }\end{array}$ & $\begin{array}{c}\text { Extra } \\
\text { americana }\end{array}$ \\
\hline Comestibles & $122.010,00$ & 53,84 & 25,46 & 28,35 & 0,03 \\
\hline $\begin{array}{l}\text { Salarios y gastos de } \\
\text { gestión }\end{array}$ & $67.407,13$ & 29,74 & 29,27 & 0,42 & 0,05 \\
\hline $\begin{array}{l}\text { Gastos de } \\
\text { campamento }\end{array}$ & $37.202,31$ & 16,42 & 6,31 & 7,07 & 3,04 \\
\hline Totales & $226.619,44$ & 100,00 & 61,04 & 35,84 & 3,12 \\
\hline
\end{tabular}

Fuente: Elaboración propia a partir de AGN, IX 4-4-2; IX 4-4-3; IX 4-4-4.

A través del seguimiento de los gastos del Sitio, se pudo establecer que la economía de la región rioplatense fue la más dinamizada por la satisfacción de las demandas, ya que absorbió 61,04\% de los gastos generales del Sitio.

De este importe, los gastos en la categoría "comestibles" (Cuadro 2) abarcaron 25,46\%; de éstos el mayor gasto lo representaron las harinas y panificados con 22,53\%, en particular los proveedores de bizcocho ordinario (la mayoría bizcocheras) que sumaron alrededor de $20 \%$ del total general gastado en la contienda. 
Cuadro 2: Gastos de la categoría “comestibles”, divididos en subcategorías

\begin{tabular}{|l|r|r|r|r|r|r|}
\hline \multicolumn{9}{|c|}{} \\
\hline Sub categorías & $\begin{array}{c}\text { Pesos de 8 } \\
\text { reales }\end{array}$ & $\begin{array}{c}\text { \% dentro } \\
\text { de la } \\
\text { categoria }\end{array}$ & $\begin{array}{c}\text { \% del } \\
\text { total } \\
\text { general }\end{array}$ & Local & $\begin{array}{c}\text { Americana } \\
\text { extra } \\
\text { regional }\end{array}$ & $\begin{array}{c}\text { Extra } \\
\text { americana }\end{array}$ \\
\hline $\begin{array}{l}\text { Vegetales o } \\
\text { derivados secos }\end{array}$ & $51.583,69$ & 42,30 & 22,76 & 0,00 & 22,76 & 0,00 \\
\hline $\begin{array}{l}\text { Harinas y } \\
\text { panificados }\end{array}$ & $51.060,44$ & 41,85 & 22,53 & 22,53 & 0,00 & 0,00 \\
\hline Alcohol o derivados & $12.664,25$ & 10,38 & 5,59 & 0,00 & 5,59 & 0,00 \\
\hline $\begin{array}{l}\text { Animales u origen } \\
\text { animal }\end{array}$ & $4.461,56$ & 3,65 & 1,97 & 1,97 & 0,00 & 0,00 \\
\hline Minerales & $1.837,94$ & 1,50 & 0,81 & 0,81 & 0,00 & 0,00 \\
\hline $\begin{array}{l}\text { Cereales o } \\
\text { legumbres }\end{array}$ & 240,38 & 0,20 & 0,11 & 0,09 & 0,00 & 0,02 \\
\hline Vegetales frescos & 133,75 & 0,10 & 0,06 & 0,06 & 0,00 & 0,00 \\
\hline Especias & 28,00 & 0,02 & 0,01 & 0,00 & 0,00 & 0,01 \\
\hline Total Comestibles & $122.010,00$ & 100,00 & 53,84 & 25,46 & 28,35 & 0,03 \\
\hline
\end{tabular}

Fuente: Elaboración propia a partir de AGN, IX 4-4-2; IX 4-4-3; IX 4-4-4.

Por su parte, los gastos ocasionados por los proveedores de la categoría "salarios y gastos de gestión" (Cuadro 3) sumaron cerca del 30\% del total de esos gastos dinamizadores de la economía local; dentro de este importe, se destacan los gastos en transporte, en especial los lancheros y los carreteros.

Cuadro 3: Gastos de la categoría “Salarios y gastos de gestión”, divididos en subcategorías

\begin{tabular}{|l|r|r|r|r|r|r|}
\hline \multicolumn{1}{|c|}{} \\
\hline Sub categoría & $\begin{array}{c}\text { Pesos de 8 } \\
\text { reales }\end{array}$ & $\begin{array}{c}\text { \% dentro } \\
\text { de la } \\
\text { categoría }\end{array}$ & $\begin{array}{c}\text { \% del total } \\
\text { general }\end{array}$ & Local & $\begin{array}{c}\text { Americana } \\
\text { extra } \\
\text { regional } \\
\text { dinamizan }\end{array}$ & \multicolumn{2}{c|}{$\begin{array}{c}\text { Extra de las esferas económicas que los gastos } \\
\text { americana }\end{array}$} \\
\hline Salarios y pagos & $48.217,31$ & 71,50 & 21,28 & 21,28 & 0,00 & 0,00 \\
\hline Transporte & $16.505,31$ & 24,50 & 7,28 & 6,86 & 0,42 & 0,00 \\
\hline $\begin{array}{l}\text { Gastos administra- } \\
\text { tivos }\end{array}$ & $2.684,50$ & 4,00 & 1,18 & 1,13 & 0,00 & 0,05 \\
\hline $\begin{array}{l}\text { Total Salarios y gas- } \\
\text { tos de gestión }\end{array}$ & $67.407,13$ & 100,00 & 29,74 & 29,27 & 0,42 & \\
\hline
\end{tabular}

Fuente: Elaboración propia a partir de AGN, IX 4-4-2; IX 4-4-3; IX 4-4-4.

Por último, el resto de los gastos dinamizadores de la economía rioplatense (Cuadro 
4) lo aportan el poco más de 6\% que suman los gastos de la categoría "gastos de campamento", en particular los proveedores de oficios con 4,55\%, gastos ocasionados principalmente por los carpinteros, los herreros y los armeros.

Cuadro 4: Gastos de la categoría "Gastos de campamento", divididos en subcategorías

\begin{tabular}{|l|r|r|r|r|r|r|}
\hline \multicolumn{2}{|c|}{} & & \multicolumn{3}{c|}{ \% de las esferas económicas que los } \\
gastos dinamizan
\end{tabular}

Fuente: Elaboración propia a partir de AGN, IX 4-4-2; IX 4-4-3; IX 4-4-4

La Corona, con sus demandas, generó trabajo a una amplia gama de proveedores; lo que puede haber ayudado también a crear fidelidad no sólo dentro del espacio rioplatense, sino del espacio americano y extra-americano. Los proveedores serían fieles a quien les diera trabajo. A la vez, se estaba internalizando el sistema de dominación, dado que la subsistencia de esos sectores sociales medios y bajos, dependía de las demandas que la corona generase.

Centrando el análisis en los propios proveedores de bienes y servicios emergieron algunos individuos que por la cantidad de transacciones y los montos involucrados no se permite integrarlos a los sectores bajos, pero tampoco a las elites, dado que tras rastrearlos no se ha podido encontrarlos en los ámbitos de pertenencia propios de este sector social. Se pudo establecer que estos individuos no participaron en corporaciones de defensa de 
intereses sectoriales, ni en el cabildo, con lo que podemos suponerlos subordinados a las elites que sí participaban de esos espacios. Este sector "medio" está integrado por un conjunto de actores que mueven sumas considerables de dinero resultante de enlazar actividades productivas y consumidores, pero que no participan de las instancias de decisión a nivel local. Son aquellos "proveedores-intermediarios"(el caso de los comerciantes proveedores o de los que abastecen debido a su función dentro de la contienda: capitanes, tenientes, alféreces), pequeños "empresarios" con capacidad de gestión que organizaban diversos trabajos (por ejemplo las bizcocheras de consideración quienes estaban presentes en unidades habitacionales complejas, en las que además del núcleo familiar se declara la presencia de indios conchabados, esclavas, mujeres libres agregadas; o de aquellas bizcocheras que formaban "clanes" familiares). ${ }^{33}$

Con respecto a los diversos proveedores, se pudo establecer el grado de especialización que había en torno a la satisfacción de las distintas demandas evidenciadas para la contienda.

Como puede observarse en el Cuadro 5, en el caso de los proveedores de comestibles, más del 78\% de ellos fue "mono-proveedor". Estos abastecedores con sus provisiones sumaban una cifra cercana a la mitad del dinero gastado en la categoría comestibles. También se pudo observar el gran peso económico de estos "mono-proveedores" en relación con los gastos totales del sitio, ya que representaban un cuarto del total de esos gastos.

En cuanto a los proveedores de servicios asociados a la logística y la gestión del sitio (Cuadro 6), más de 90\% proveyeron un solo servicio. Estos abastecedores tuvieron un gran peso económico en relación con los gastos dentro de la categoría "Salarios y gastos de gestión", ya que representaban alrededor de 60\% del total de esos gastos. También fueron significativas estas sumas de dinero con respecto al total de los gastos del sitio, ya que sumaron $17,67 \%$ del dinero gastado en la contienda.

\footnotetext{
${ }^{33}$ Hay cientos de entregas de productos a lo largo del período en que duró el sitio, las mismas se encuentran esparcidas en todos los legajos, en la parte de data del Proveedor, o sea a quién el Proveedor Real le dio el producto para su distribución, ver AGN, IX 4-4-2; IX 4-4-3 y IX 4-4-4.
} 
Cuadro 5: Proveedores de la categoría "comestibles", distribuidos por cantidad de bienes provistos y peso económico de sus provisiones

\begin{tabular}{|c|r|r|r|r|r|}
\hline $\begin{array}{c}\text { Bienes } \\
\text { provistos }\end{array}$ & $\begin{array}{c}\text { Cantidad de } \\
\text { proveedores }\end{array}$ & $\begin{array}{c}\text { \% del total } \\
\text { general de } \\
\text { proveedores }\end{array}$ & $\begin{array}{c}\text { Pesos 8 reales } \\
\text { de sus } \\
\text { provisiones }\end{array}$ & $\begin{array}{c}\text { \% dentro de la } \\
\text { categoría }\end{array}$ & $\begin{array}{c}\text { \% del total } \\
\text { general de gastos del } \\
\text { Sitio }\end{array}$ \\
\hline 1 & 129 & 78,20 & $56.741,81$ & 46,50 & 25,04 \\
\hline 2 & 23 & 13,95 & $31.319,81$ & 25,67 & 13,82 \\
\hline 3 & 5 & 3,05 & $10.397,81$ & 8,52 & 4,59 \\
\hline 5 & 3 & 1,80 & $9.369,75$ & 7,68 & 3,13 \\
\hline 6 & 2 & 1,20 & $7.277,81$ & 5,97 & 1,32 \\
\hline 4 & 2 & 1,20 & $2.983,57$ & 2,45 & 1,73 \\
\hline 13 & 1 & 0,60 & $3.919,44$ & 3,21 & 53,84 \\
\hline Totales & 165 & 100,00 & $122.010,00$ & 100,00 & \\
\hline
\end{tabular}

Fuente: Elaboración propia a partir de AGN, IX 4-4-2; IX 4-4-3; IX 4-4-4

Cuadro 6: Proveedores categoría "Salarios y gastos de gestión”, distribuidos por cantidad de servicios provistos y peso económico de sus provisiones

\begin{tabular}{|c|r|r|r|r|r|}
\hline $\begin{array}{c}\text { Bienes } \\
\text { provistos }\end{array}$ & $\begin{array}{c}\text { Cantidad de } \\
\text { proveedores }\end{array}$ & $\begin{array}{c}\text { \% del total } \\
\text { general de } \\
\text { proveedores }\end{array}$ & $\begin{array}{c}\text { Pesos 8 reales } \\
\text { de sus provi- } \\
\text { siones }\end{array}$ & $\begin{array}{c}\text { \% dentro de } \\
\text { la categoría }\end{array}$ & $\begin{array}{c}\text { \% del total gene- } \\
\text { ral de gastos del } \\
\text { Sitio }\end{array}$ \\
\hline 1 & 170 & 92,40 & $40.048,81$ & 59,40 & 17,67 \\
\hline 2 & 11 & 5,98 & $22.606,50$ & 33,54 & 9,97 \\
\hline 3 & 1 & 0,54 & $1.752,00$ & 2,60 & 0,77 \\
\hline 4 & 1 & 0,54 & 308,25 & 0,46 & 0,14 \\
\hline 5 & 1 & 0,54 & $2.691,57$ & 4,00 & 1,19 \\
\hline Totales & 184 & 100,00 & $67.407,13$ & 100,00 & 29,74 \\
\hline
\end{tabular}

Fuente: Elaboración propia a partir de AGN, IX 4-4-2; IX 4-4-3; IX 4-4-4

Por su parte, los abastecedores de bienes no comestibles y servicios relativos al campamento de la contienda, la situación fue similar a la de los proveedores de la logística pues, 70\% de ellos fueron también “mono-proveedores”. (Ver Cuadros 7 y 8).

Pese a que en todas las sub-categorías hay preponderancia de los mono-proveedores, no se ha evidenciado concentración del aprovisionamiento en unas pocas manos, sino una notable heterogeneidad dentro de los diversos rubros. Por ejemplo, respecto a los proveedores de bizcocho ordinario, al interior del grupo se observa una notable disparidad en cuanto a cantidades provistas, número de participaciones en el mercado y 
montos involucrados: Manuela de Ramila, la mayor proveedora del sitio, entregó 437,7 quintales, equivalentes al 6,19\% del total (20.107,938 kg); el clan Beresosa y Contreras abasteció 10\% del bizcocho del sitio; pero también hubo lugar para las pequeñas bizcocheras, generalmente agrupadas en clanes familiares, como las hermanas Gómez. La mayoría de los proveedores menores realiza sólo una única entrega, o al menos recibe un único pago. (Ver Cuadro 9).

Cuadro 7: Proveedores categoría "Gastos de campamento”, distribuidos por cantidad de bienes no comestibles provistos y peso económico de sus provisiones

\begin{tabular}{|c|c|c|c|c|c|}
\hline $\begin{array}{c}\text { Bienes } \\
\text { provistos }\end{array}$ & $\begin{array}{l}\text { Cantidad de } \\
\text { proveedores }\end{array}$ & $\begin{array}{l}\% \text { del total } \\
\text { general de } \\
\text { proveedores }\end{array}$ & $\begin{array}{c}\text { Pesos } 8 \text { reales } \\
\text { de sus } \\
\text { provisiones }\end{array}$ & $\begin{array}{l}\text { \% dentro de } \\
\text { la categoría }\end{array}$ & $\begin{array}{l}\text { \% del total gene- } \\
\text { ral de gastos del } \\
\text { Sitio }\end{array}$ \\
\hline 1 & 37 & 69,80 & $13.384,94$ & 35,98 & 5,90 \\
\hline 2 & 8 & 15,09 & $3.652,19$ & 9,82 & 1,61 \\
\hline 3 & 1 & 1,89 & 211,00 & 0,57 & 0,09 \\
\hline 4 & 1 & 1,89 & 189,12 & 0,50 & 0,08 \\
\hline 6 & 2 & 3,77 & $1.389,69$ & 3,73 & 0,61 \\
\hline 7 & 1 & 1,89 & 424,87 & 1,14 & 0,19 \\
\hline 8 & 1 & 1,89 & 356,00 & 0,96 & 0,16 \\
\hline 31 & 1 & 1,89 & $4.519,19$ & 12,15 & 2,00 \\
\hline 33 & 1 & 1,89 & $1.487,00$ & 4,00 & 0,66 \\
\hline Totales & 53 & 100,00 & $25.614,00$ & 68,85 & 11,30 \\
\hline
\end{tabular}

Fuente: Elaboración propia a partir de AGN, IX 4-4-2; IX 4-4-3; IX 4-4-4. 
Cuadro 8: Proveedores categoría "Gastos de campamento", distribuidos por cantidad de servicios provistos y peso económico de sus provisiones

\begin{tabular}{|c|c|r|r|r|r|}
\hline $\begin{array}{c}\text { Bienes } \\
\text { provistos }\end{array}$ & $\begin{array}{c}\text { Cantidad de } \\
\text { proveedores }\end{array}$ & $\begin{array}{c}\text { \% del total } \\
\text { general de } \\
\text { proveedores }\end{array}$ & $\begin{array}{c}\text { Pesos 8 reales } \\
\text { de sus } \\
\text { provisiones }\end{array}$ & $\begin{array}{c}\text { \% dentro de la } \\
\text { categoría }\end{array}$ & $\begin{array}{c}\text { \% del total ge- } \\
\text { neral de gastos } \\
\text { del Sitio }\end{array}$ \\
\hline 1 & 63 & 69,23 & $5.864,75$ & 15,77 & 2,59 \\
\hline 2 & 17 & 18,68 & $4.257,13$ & 11,44 & 1,88 \\
\hline 3 & 10 & 10,99 & 978,68 & 2,63 & 0,43 \\
\hline 7 & 1 & 1,10 & 487,75 & 1,31 & 0,22 \\
\hline Totales & 91 & 100,00 & $11.588,31$ & 31,15 & 5,12 \\
\hline
\end{tabular}

Fuente: Elaboración propia a partir de AGN, IX 4-4-2; IX 4-4-3; IX 4-4-4.

En cuanto a la distribución por sexo de los diversos proveedores, en la categoría comestibles estaba muy equilibrada, alrededor de 50\% de ambos, (dentro de las mujeres, la mayoría fueron bizcocheras); respecto a la categoría Salarios y gestión, 98\% fueron hombres; por último, los proveedores de los gastos de Campamento también fueron hombres casi en su totalidad, pues $97 \%$ de ellos lo eran. ${ }^{34}$

Cuadro 9: Proveedores de bizcocho ordinario, distribuidos por cantidad de producto provisto

\begin{tabular}{|l|c|r|r|r|}
\hline $\begin{array}{c}\text { Cantidad } \\
\text { quintales provista }\end{array}$ & $\begin{array}{c}\text { Cantidad de } \\
\text { proveedores }\end{array}$ & $\begin{array}{c}\text { \% del total de } \\
\text { proveedores de } \\
\text { bizcocho }\end{array}$ & $\begin{array}{c}\text { Quintales } \\
\text { entregados }\end{array}$ & $\begin{array}{c}\text { \% del total de biz- } \\
\text { cocho } \\
\text { entregado }\end{array}$ \\
\hline 437,70 a 150,00 & 9 & 8,33 & $2.068,13$ & 29,24 \\
\hline 149,99 a 80,00 & 17 & 15,74 & $1.882,53$ & 26,62 \\
\hline 79,99 a 55,00 & 13 & 12,04 & 850,23 & 12,02 \\
\hline 54,99 a 40,00 & 24 & 22,22 & $1.112,68$ & 15,73 \\
\hline 39,99 a 25,00 & 23 & 21,30 & 737,92 & 5,96 \\
\hline 24,99 a 13,17 & 108 & 100,00 & $7.072,64$ & 100 \\
\hline Totales & 22 & & 421,15 & 10,43 \\
\hline
\end{tabular}

Fuente: Elaboración propia a partir de AGN, IX 4-4-2; IX 4-4-3; IX 4-4-4.

En su mayoría los bienes y/o servicios fueron brindados en el espacio rioplatense a las compañías de naturales y pardos destinadas a la expedición a Colonia de Sacramento, a

${ }^{34}$ AGN, IX 4-4-2, IX -4-4-3 y IX 4-4-4. 
María Emilia Sandrín

las compañías de la Ensenada de Barragán, a las del camino del Carcarañá, a los soldados asentados en Montevideo, $\mathrm{y}$ a todas aquellas tropas intervinientes en la contienda. ${ }^{35}$

A través de estos estudios también se ha podido establecer la heterogeneidad de trabajos que la satisfacción de las demandas de los barcos generaban en el espacio rioplatense: pequeñas bizcocheras, pequeños productores/recolectores (de leña o carbón), herreros, carpinteros, armeros, zapateros, silleros, albañiles, plateros, caldereros, toneleros, carreteros, lancheros, marineros, diversos peones (que hacían guardias, vigilaban las costas, romaneaban las cargas), por mencionar sólo algunos de los tantos modos de vida de los integrantes del sector social bajo. Se ha evidenciado distintas categorías de "proveedores"; entre los carpinteros y armeros, hubo maestros, oficiales y peones; por parte de los herreros, había maestros y peones; cuando prestaban más de un servicio, compartían la "jerarquía" dentro de ese oficio que estaban brindando. ${ }^{36}$ Hubo quienes por su cargo y/o función abastecían a las tropas; fueron los casos de los capitanes, tenientes, alférez, condestable de la artillería, sobrestante, guarda almacén, o el propio proveedor real ${ }^{37}$; también hubo quienes cobraron por brindar su profesión (práctico de río, ingeniero, cirujano, boticario, capellán, cocinero, entre otros) ${ }^{38}$.

\section{Los proveedores de bienes y servicios para el Carenado y Calafateado de las Fragatas-correo en Montevideo 1767-1802 ${ }^{39}$}

Además de lo relacionado con el mantenimiento de las tripulaciones en tierra y los bastimentos para el tornaviaje, desde la llegada de un navío a puerto se creaba una demanda constante de bienes y mano de obra, para reparar los daños sufridos en el viaje o contrarrestar el envejecimiento durante las estadías, así como para que el navío estuviera en las mejores condiciones posibles a la hora de emprender el regreso.

La fuente base para analizar estas actividades económicas y los individuos que las llevaron a cabo es el "libro de carenas" ${ }^{0}$ de las Fragatas-correo que comenzaron a llegar

${ }^{35}$ AGN, IX 4-4-2, IX -4-4-3 y IX 4-4-4.

${ }^{36}$ AGN, IX 4-4-2, IX -4-4-3 y IX 4-4-4.

${ }^{37}$ Como Isidro Molina capitán de una compañía, Pedro Vieyra integrante de la compañía de artillería y José Narriondo soldado de la compañía del capitán don Francisco Gutiérrez; todos proveyeron socorros para la curación de heridas.

${ }^{38}$ Santos de Barzena, fue el boticario de la expedición y también cumplió ese rol para los navíos de registro. AGN, IX 43-2-4, leg. 17, exp. 3; IX 43-1-6, leg. 9, exp. 2. Francisco de la Plaza, fue cirujano del sitio. Juan Sinot, fue cocinero del Hospital volante; Felipe de la Vega, fue capellán de la expedición. AGN, IX 4-4-3.

39 Para un mayor detalle acerca de los proveedores de las Fragatas-correo, participación económica y demás ver M. Sandrín, “Carpinteros, calafates, herreros”. M. Sandrín, "La demanda de bienes”. M. Sandrín, "Las fuentes fiscales”.

$4^{\circ 0}$ La carena de un navío consistía en “... el reparo que se hace en los navíos, quitándoles la carcoma, y tapando, y calafeteando los agujeros y las grietas con estopa y brea, para que no reciban agua, y puedan navegar” Diccionario de la Real Academia, edición de 1729, www.rae.es (consulta 5/03/2019). Aparentemente, se extendió la idea hasta abarcar todas las reparaciones y servicios necesarios para mantener a los barcos en "condiciones marineras", como se solía decir. 
al Río de la Plata en $1767 .{ }^{41}$ Además de su utilidad específica esta fuente permite ver cómo la navegación dejaba sentir su presencia en Montevideo, puerto de destino de las Fragatas-correo. Este libro cubre el período 1767-1802, y da cuenta del mantenimiento de 30 Fragatas-correo que realizaron en total 166 viajes entre Montevideo y La Coruña.

En este libro, el Administrador de la Real Renta de Correos en Montevideo, Melchor de Viana, detalla día a día los gastos hechos en la provisión de todos los bienes y servicios necesarios para el carenado y calafateado de las embarcaciones. Figuran los datos de a quién se le pagó el producto y/o el servicio, la fecha de pago, el bien y/o servicio y a cuánto se le pagó, si se le está pagando por pieza, por día, por mes, por tarea terminada, el destino del bien y/o servicio, en el caso de insumos muchas veces se indica para qué trabajo se usaría, en casos excepcionales se menciona también el lugar de residencia del proveedor, entre tantos datos.

La fuente permitió obtener un total general de los gastos ocasionados por el carenado y calafateado de las Fragatas-correo y revelar, mediante el seguimiento de la satisfacción de las diversas demandas, la dinamización que esta navegación pudo originar en las distintas esferas económicas: la local, la americana extra regional o la extra americana; a la vez que se pudo registrar cada uno de los aprovisionamientos realizados por cada proveedor involucrado en la satisfacción de las distintas demandas. Al igual que para el caso testigo anterior analizado en este trabajo, una vez que se identificaron cada uno de estos proveedores de bienes y servicios, para empezar a reconstruir las redes de relaciones puestas en acción para satisfacer las respectivas demandas, se investigó sobre sus vidas en diccionarios biográficos, censos, padrones, fuentes judiciales, entre otras fuentes.

Los sectores sociales ajenos a la elite, dedicados en Montevideo a satisfacer las necesidades de las Fragatas-correo para su mantenimiento en condiciones marineras, tuvieron trabajo de forma regular, al menos a lo largo de los 35 años que duró el mantenimiento de todas estas embarcaciones. Los diversos trabajos estuvieron distribuidos de manera más o menos uniforme a lo largo de todo el período, pues si bien hubo tareas en las que no se pudo establecer bien el año en que fueron cumplidas, éstas se tienen que haber realizado en el período que los barcos estaban parados.

Observando la participación económica de los proveedores desagregados se puede advertir que las sumas se distribuían ampliamente y con participaciones diversas; aquí puede verse cómo el efecto de la circulación ultramarina se distribuía sobre muchos individuos.

${ }^{41}$ AGN, XIII-15-6-2. 
No siempre se pudo identificar a los proveedores de las diversas categorías en que fueron divididos los gastos ocasionados para el carenado y calafateado de las Fragatas-correo, no obstante, pese a este impedimento, se han podido esbozar varias reflexiones sobre su condición socio-económica.

Un aspecto a resaltar es que eran hombres todos los individuos que participaron de las diversas tareas necesarias para el carenado y calafateado de las Fragatas-correo, ya que no se evidenció en las fuentes participación femenina proveyendo algún bien y/o servicio para estas embarcaciones.

Cuadro 10: Carenado Fragatas-correo, 1767-1802. Gastos totales.

Distribución por Categorías y proporción de las esferas económicas dinamizadas

\begin{tabular}{|l|r|r|r|r|r|}
\hline \multicolumn{1}{|c|}{$\begin{array}{c}\text { \% de las esferas económicas que los gastos } \\
\text { dinamizan }\end{array}$} \\
\hline Categorias & $\begin{array}{c}\text { Gastos en pesos } \\
\text { de 8 reales } \\
\text { valor total } \\
\text { carena }\end{array}$ & Local & \multicolumn{1}{c|}{$\begin{array}{c}\text { Americana } \\
\text { extra } \\
\text { regional }\end{array}$} & $\begin{array}{c}\text { Extra } \\
\text { americana }\end{array}$ \\
\hline Oficios & $57.966,49$ & 56,08 & 56,08 & 0,00 & 0,00 \\
\hline Compras & $42.901,19$ & 41,51 & 28,57 & 7,23 & 5,71 \\
\hline Transporte & $2.075,00$ & 2,00 & 2,00 & 0,00 & 0,00 \\
\hline Gastos & 420,50 & 0,41 & 0,41 & 0,00 & 0,00 \\
\hline Totministrativos & $103.363,18$ & 100,00 & 87,06 & 5,23 & \\
\hline
\end{tabular}

Fuente: elaboración propia a partir de AGN, XIII-15-6-2

Como puede observarse en el Cuadro 10, de todas las categorías creadas para analizar los gastos totales de las carenas, la categoría “Oficios” sumó 56,o8\% del total, por lo que se convirtió en la categoría que más dinero insumió en el mantenimiento de las Fragatas-correo. Se crearon diversas sub-categorías para ampliar el análisis de estos oficios, identificándose, por orden de participación económica: los calafates, los estibadores/ arrumadores, los herreros, los carpinteros, los faroleros/caldereros/latoneros/estañadores, los toneleros, los albañiles y los aserradores, armeros, buzos, pintores y cocedores de brea (ver Cuadro 11). 
Cuadro 11: Gastos de la categoría "Oficios" divididos en subcategorías

\begin{tabular}{|l|r|r|r|r|r|r|}
\hline \multicolumn{1}{|c|}{} & \multicolumn{9}{c|}{$\begin{array}{c}\text { \% de las esferas económicas que los } \\
\text { gastos dinamizan }\end{array}$} \\
\hline Sub-categorías & $\begin{array}{c}\text { Gastos en } \\
\text { pesos de 8 } \\
\text { reales }\end{array}$ & $\begin{array}{c}\text { \% dentro } \\
\text { de la } \\
\text { categoría }\end{array}$ & $\begin{array}{c}\text { \% } \\
\text { sobre valor } \\
\text { total } \\
\text { carena }\end{array}$ & Local & $\begin{array}{c}\text { Americana } \\
\text { extra } \\
\text { regional }\end{array}$ & \multicolumn{1}{c|}{$\begin{array}{c}\text { Extra } \\
\text { americana }\end{array}$} \\
\hline calafates & $24.488,25$ & 42,25 & 23,69 & 42,25 & 0,00 & 0,00 \\
\hline $\begin{array}{l}\text { estibadores/arru- } \\
\text { madores }\end{array}$ & $10.683,93$ & 18,43 & 10,33 & 18,43 & 0,00 & 0,00 \\
\hline herreros & $8.080,45$ & 13,94 & 7,82 & 13,94 & 0,00 & 0,00 \\
\hline carpinteros & $7.822,62$ & 13,49 & 7,57 & 13,49 & 0,00 & 0,00 \\
\hline $\begin{array}{l}\text { faroleros/calde- } \\
\text { reros/latoneros/ } \\
\text { estañadores }\end{array}$ & $4.111,37$ & 7,09 & 3,98 & 7,09 & 0,00 & 0,00 \\
\hline toneleros & $1.959,37$ & 3,38 & 1,90 & 3,38 & 0,00 & 0,00 \\
\hline albañiles & 432,50 & 0,75 & 0,42 & 0,75 & 0,00 & 0,00 \\
\hline oficios varios & 388,00 & 0,67 & 0,37 & 0,67 & 0,00 & 0,00 \\
\hline Totales & $57.966,49$ & 100,00 & 56,08 & 100,00 & 0,00 & 0,00 \\
\hline
\end{tabular}

Fuente: elaboración propia a partir de AGN, XIII-15-6-2.

A lo largo de los 35 años analizados se pudo identificar que hubo oficios que fueron apareciendo con el correr del tiempo; es el caso de los estañadores, tarea que primeramente era realizada por los faroleros y que recién hace su aparición al final del período; lo que puede presuponer una mayor especialización del trabajo en la ciudad de Montevideo ocasionada por el crecimiento de la ciudad y la intensificación del tráfico. Es decir, una ampliación de este sector social medio entre las elites y los estratos más bajos.

Hubo oficios en los cuales la participación económica de los individuos que los proveían fue muy pareja en los montos cobrados, sin llegar a haber concentración por parte de unos pocos individuos. Fue el caso de los carpinteros; donde el mayor proveedor de esta subcategoría cobró sólo 1,17\% del total general recibido por los carpinteros, mientras que los demás proveedores identificados de este oficio tuvieron pequeñas participaciones económicas en cuanto al conjunto, pero, pese a ser pequeños los montos cobrados fueron muy redituables. También hubo rubros en los que los trabajos estuvieron acaparados por diversos individuos y/o grupos de personas. Fueron los casos de los herreros, donde sólo seis individuos realizan esta tarea a lo largo de los 33 años que se necesitaron trabajos de herrería. Dentro de este reducido grupo, Zufriategui concentra 100\% de los trabajos de un año, Embil 96,98\% de las tareas de este oficio de una década, Osinaga 
María Emilia Sandrín

59,26\% de los trabajos de un año y este mismo individuo luego abarca 93,18\% de las tareas de herrería a lo largo de 20 años. También hubo concentración en la subcategoría toneleros, donde José Raimundo Figueroa realiza 44,03\% de las tareas de su oficio a lo largo de 14 años; en la subcategoría albañiles donde José Patricio de Farías en sólo 5 años abarca 31,30\% de los trabajos de su oficio; y el caso de Ignacio Prat, un armero que cobró $57,24 \%$ de las tareas de su oficio.

Una reflexión derivada de lo anterior es que los trabajos de estos proveedores de diversos oficios necesarios para mantener a las embarcaciones en condiciones marineras eran bien remunerados. Por citar un ejemplo, los pocos trabajos realizados por el herrero Juan Ángel Embil le alcanzaban para cubrir el costo anual del alquiler de una importante casa. Otro caso de alto rendimiento en su trabajo lo muestra el carpintero José Argote, si este individuo alquilaba el cuarto en que vivía, con el 60\% de lo obtenido en 8 días de labor habría cubierto el alquiler de 1771.

Varios trabajadores de las Fragatas-correo figuran con su oficio declarado en los padrones de la época; fueron los casos de Tomás Soriano, quien también ya aparecía en el padrón de 1772-1773 revistando como calafate; Ignacio Prat, el armero del regimiento de infantería; o el herrero Francisco de Zufriategui. ${ }^{42}$

Hubo trabajadores que desarrollaron más de un oficio en este carenado de las Fragatas-correo. Argote fue herrero, carpintero y también calafate; Antonio Moreno, un calafate que como tonelero compuso pipas de la aguada, a la vez que efectuó compras de alquitrán y velas; Francisco Gutiérrez un calafate que como carretero llevó leña a las Fragatas-correo para ser usada en la cocción de la brea; Francisco Zubillaga, realizó trabajos de carpintero y calafate en el mismo año 1791; José Arias fue estibador y carpintero; Agustín Sánchez y Andrés Vidal, identificados como maestros faroleros, caldereros y latoneros/estañadores. 43

Se han identificado trabajadores de diversos oficios viviendo en la misma casa; el caso emblemático es la "gran casa” de Juan Embil, un herrero con casa con pulpería

\footnotetext{
${ }^{42}$ Por ejemplo, Tomás Soriano, ya aparecía en el padrón de 1772-1773 revistando como calafate "identificado como vecino, de edad 40 años, casado, con 6 hijos (...) de oficio calafate”. Juan A. Apolant, Padrones olvidados de Montevideo del siglo XVIII. I y II, Montevideo, Imprenta Letras, Separata de Boletín Histórico, Estado Mayor del Ejército, 104-105 y $106-107,1966$, p. 78.

${ }^{43}$ AGN, XIII-15-6-2.
} 
y múltiples y versátiles ocupantes, desde herreros, carpinteros, estibadores, un zapatero ${ }^{44}$. También se han observado trabajadores del mismo oficio viviendo en el mismo domicilio, como los carpinteros Martín de Irazogui y su oficial Martín de Aguirre. ${ }^{45}$

Posiblemente haya trabajadores emparentados entre sí, como los estibadores/ arrumadores José y Felipe Arias, o el de Joaquín y Antonio Sánchez, quienes figuran cobrando en el mismo tiempo por sus tareas; o los calafates Francisco y José Ortiz, Juan y José de León, Miguel y Antonio Moreno, Santiago, Francisco y José Gutiérrez, entre otros. ${ }^{46}$

Se ha podido identificar distintas categorías de trabajadores, hubo oficiales, maestros, ayudantes, peones, aprendices; como así también la presencia de rubros subsidiarios de otros rubros mayores, fue el caso de los aserradores, oficio surgido como complemento a la carpintería.

Con respecto a los pagos, hubo trabajadores que cobraron por jornal, otros por tarea/producto terminada/o, un dato particular es que a los trabajadores de a bordo de la embarcación se les pagaba medio jornal.

También se han observado proveedores de oficios pertenecientes a determinada embarcación, como los maestros toneleros Juan del Río, Pedro Merino y Baltasar Rodríguez, de las fragatas Santa Bárbara, Nuestra Señora de la Concepción y la Industria respectivamente. ${ }^{47}$

La provisión de insumos por parte de los proveedores de oficio fue una fuente más de dinamización de la economía rioplatense, de la americana extra regional o de la extra americana. Juan de Aguirre fue un calafate que cobró por provisión de estopa, lonas, perchas, cueros y sebo. José de Aguirre fue un carpintero que abasteció maderas. Otro carpintero fue Juan Bautista Arriola quien compró maderas, roldanas, cureñas, materiales para el fogón, gallineros, clavos. O Ignacio Montero, un calafate que también

\footnotetext{
${ }^{44}$ En 1772-1773, J. A. Embil tenía 50 años, es calificado como vecino de Montevideo en el padrón aunque su esposa estaba en Vizcaya. Además de declarar por oficio la herrería, tenía una pulpería en su casa y en un cuarto vivía otro natural de Vizcaya, José Argote, un herrero y carpintero de 25 años de edad. J. Apolant, "Padrones olvidados de Montevideo", p. 83 .

${ }^{45}$ AGN, XIII-15-6-2.

${ }^{46}$ AGN, XIII-15-6-2.

${ }^{47}$ AGN, XIII-15-6-2.
} 
compró maderas. Un caso particular lo representan los albañiles quienes en varias oportunidades fueron ellos mismos quienes proveyeron los diversos materiales necesarios para los arreglos de su oficio. ${ }^{48}$

Como puede observarse en el cuadro 10, la segunda categoría que más dinero insumió en el mantenimiento de las Fragatas-correo fue la categoría "Compras". Los proveedores incluidos en ella sumaron $41,51 \%$ del total gastado en todas las carenas; dividiéndose para un mejor análisis en dos subcategorías, "Elementos de la carena propiamente dicha" y "Elementos complementarios a la carena" (ver cuadro 12).

Cuadro 12: Carenado Fragatas-correo (1.767-1.802). Compras. Distribución por sub categorías. Proporción del impacto de cada sub categoría en los gastos totales de las Carenas. Distribución de los gastos por esferas económicas dinamizadas en relación con los gastos totales

\begin{tabular}{|l|r|r|r|}
\hline \multicolumn{4}{|c|}{$\begin{array}{c}\text { \% de las esferas económicas } \\
\text { que los gastos dinamizan }\end{array}$} \\
\hline Sub-categorías & \multicolumn{1}{|c|}{ Local } & $\begin{array}{c}\text { Americana extra } \\
\text { regional }\end{array}$ & Extra americana \\
\hline Elementos de la carena propiamente dicha & 21,22 & 6,29 & 5,70 \\
\hline Elementos complementarios a la carena & 7,35 & 0,94 & 0,01 \\
\hline Totales & 28,57 & 7,23 & 5,71 \\
\hline
\end{tabular}

Fuente: elaboración propia a partir de AGN, XIII-15-6-2.

Hubo insumos en los cuales la participación económica de los individuos que los proveían fueron muy parejas en los montos cobrados, sin llegar a haber concentración por parte de unos pocos individuos. Fue el caso de la provisión de leña, de los materiales para el fogón, o las maderas. Con respecto a estas últimas, si bien hay tres mayores proveedores que entregan cerca de $30 \%$ de las maderas necesarias para las carenas, el resto fueron provistas por los 70 proveedores restantes, con participaciones económicas similares, ya que entregaron cada uno un promedio de 1,04\% del total económico gastado en este insumo. Otro ejemplo de esta distribución económica similar son los proveedores de velas; donde no hubo individuos que acaparasen por largo tiempo las entregas, ni proveedores que abastezcan ellos solos 20\% o más de este insumo (el mayor proveedor sólo entregó 14,29\% del total, a lo largo de los siete años que duraron sus abastecimientos). ${ }^{49}$

${ }^{48}$ AGN, XIII-15-6-2.

${ }^{49}$ AGN, XIII-15-6-2. 
También hubo bienes en los que las entregas estuvieron acaparadas por diversos individuos. Fueron los casos de los proveedores de piedra, donde sólo dos de ellos abarcaron $87,92 \%$ del total (las ventas del mayor proveedor, equivalieron a 45,61\% del total, mientras que el segundo mayor abastecedor cubrió 42,31\% del total gastado en este producto). José Durán concentró la provisión de remos, entregando 57,14\% de los mismos. Francisco de Gueselaga, fue el mayor proveedor de marquetas de cuero, abasteciendo 55\% del total gastado en ellas. Con respecto a los proveedores de suelas, a los tres mayores proveedores les pagan por 34,72\%, 16,20\% y 10,38\% del total gastado en este insumo, respectivamente. También las entregas de cueros estuvieron acaparadas por pocos individuos, Pedro de Barrenechea; entregó 25,16\% del total, seguido en importancia por las cantidades entregadas de este insumo por Zacarías Pereyra, quien abasteció $16,51 \%$ del total. ${ }^{50}$

Varios proveedores de insumos necesarios al carenado de las Fragatas-correo figuran con su oficio declarado en los padrones de la época; fueron los casos de los comerciantes Pedro de Barrenechea, Javier Echenique, Franciso Mont; del pulpero Francisco de Gueselaga. ${ }^{51}$

Hubo comerciantes, vinculados a la artillería, como Esteban Marzal y José María Bruno, que participan además del negocio del carenado y calafateado abasteciendo los mismos productos que venden, coronando seguramente buenos negocios. ${ }^{52}$ Hay que pensar que en este trabajo sólo se analizan los abastecimientos de bienes necesarios para las Fragatas-correo de Montevideo, pero que fueron una gran cantidad las embarcaciones que necesitaron indispensablemente carenarse y calafatearse para ponerse en “condiciones marineras" y poder regresar a España. Hay que tener en cuenta que para épocas anteriores esta misma relación comerciantes-funcionarios abastecedores fue evidenciada en el aprovisionamiento a las tropas de un conflicto bélico. ${ }^{53}$

\footnotetext{
${ }^{50}$ AGN, XIII-15-6-2.

${ }^{51}$ Pedro de Barrenechea, además de los 3.251 cueros para forrar la bodega vendió estopa; brea; 20 barriles, 405,5 arrobas y 101 libras de sebo; 26 barriles para contener sebo; velas; maderas; materiales para la construcción del fogón; 16,25 fanegas de cal para componer el fondo de la embarcación. Un dato muy particular es que don Pedro figura en el padrón de 1772-1773, en la Segunda Compañía de vecinos, en El Pueblo, como "capitán (...) vecino, de edad 54 años, soltero; comerciante", viviendo en su casa con Francisco Gueselaga, "natural de Vizcaya, edad 26 años, soltero, pulpero". quien también abasteció a las Fragatas-correo de estopa; velas; sebo; marquetas de cuero, barriles para el sebo y pipas para la aguada. En la misma casa vivían además el oficial Juan Francisco Otaegui, "su edad 26 años, soltero, vizcaíno (...) de oficio carpintero" quien vendió maderas para hacer espeques para la artillería; Esteban Marzal, otro comerciante "natural de la Coruña, edad 42 años, casado en Castilla (...) alistado en la artillería” que vendió velas, sebos y barriles para contener a estos últimos; y Javier Echenique, "natural de Vizcaya, su edad 26 años, soltero, dependiente de la casa de los señores Ustariz”, también abastecedor de maderas (para pasamanos, bandas, cofas, la caña del timón) alquitrán, perchas, jarcias para las Fragatas-correo. J. Apolant, "Padrones olvidados de Montevideo”, p. 71.

$5^{2}$ AGN, XIII-15-6-2.

${ }^{53}$ Ver M. Sandrín “Bizcocheras, lancheros y demás”.
} 
Otros pertrechos fueron provistos por individuos que tenían un cargo específico; como el Ministro de Marina, por el Guarda almacén y el Contador de Marina, José Benito Barrios. ${ }^{54}$

Hubo trabajadores que proveyeron más de un producto y/o servicio en este carenado de las Fragatas-correo. Francisco Gutiérrez es un calafate que como carretero llevó leña para ser usada en la cocción de la brea; los pilotos José Santelices, Manuel Trellez, Francisco Rivero y los carreteros Francisco Gutiérrez, Antonio Giménez, Antonio Miraballes que entregaron leña. Pedro de Barrenechea, abasteció sebo, estopa, brea, maderas, materiales para el fogón, cueros, cal y barriles para contener sebo. Pedro Subiela (otro fabricante de velas) proveyó sebo, comida, cueros y velas, a la vez que fue uno más de los albañiles que compuso el fogón. Gregorio Pérez abasteció sebo y también entregó saleas, cueros e importantes cantidades de velas. Juan Francisco García de Zúñiga, un maestro de velas que proveyó sebo y también barriles para contener y/o transportarlo. ${ }^{55}$

Cuadro 13: Carenado Fragatas-correo (1.767-1.802). Transporte. Distribución por subcategorías. Proporción del impacto de cada sub categoría en los gastos totales de las Carenas. Distribución de los gastos por esferas económicas dinamizadas en relación con los gastos totales

\begin{tabular}{|l|r|r|r|}
\hline \multicolumn{7}{|c|}{$\%$ de las esferas económicas que los gastos dinamizan } \\
\hline Subcategorías & Local & Americana extra regional & Extra americana \\
\hline Fletes de lancha & 1,54 & 0,00 & 0,00 \\
\hline Carretero & 0,16 & 0,00 & 0,00 \\
\hline Carretillero & 0,15 & 0,00 & 0,00 \\
\hline Mandadero & 0,10 & 0,00 & 0,00 \\
\hline Uso de bueyes & 0,05 & 0,00 & 0,00 \\
\hline Totales & 2,00 & 0,00 & 0,00 \\
\hline
\end{tabular}

Fuente: elaboración propia a partir de AGN, XIII-15-6-2

${ }^{54}$ AGN, XIII-15-6-2.

${ }^{55}$ AGN, XIII-15-6-2. 
Se han identificado a proveedores de diversos insumos viviendo en la misma casa; el caso del comerciante que más productos abasteció para las carenas, Pedro de Barrenechea, quien vivía en su casa junto a un pulpero, un oficial carpintero, otro comerciante alistado en la artillería, y un comerciante dependiente de casa comercial española; todos abastecedores tanto de bienes como de servicios para las Fragatas-correo. ${ }^{56} \mathrm{O}$ el caso de José María Bruno, el pulpero alistado en la artillería que tenía arrimado en su casa al carretero Fernando Requejo. ${ }^{57}$ Esta característica de "compartir casa" parecería ser una constante pues esto mismo fue observado en los proveedores de oficios, de estas Fragatas-correo y en los proveedores de comestibles, transportes, oficios y demás del Sitio a Colonia del Sacramento.

Posiblemente haya trabajadores emparentados entre sí, como en rubros como el aprovisionamiento de cueros, en el que se han identificado proveedores con posibles lazos familiares entregando este producto; es el caso de Luis y Francisco Antonio Maciel; Rudesindo y Diego Sáenz; Juan y Andrés Vázquez. ${ }^{8}$

También se han observado proveedores de oficios pertenecientes a determinada embarcación, los pilotos José Santelices, Manuel Trellez, Francisco Rivero y los carreteros Francisco Gutiérrez, Antonio Giménez, Antonio Miraballes que entregaron leña; algunos de ellos proveyeron también comida. José de Aguirre, maestre de la Fragata La Limeña quien abasteció maderas. ${ }^{59}$ La participación económica de los lancheros, carreteros, carretilleros, mandaderos y demás, incluidos en la categoría "Transportes”, sumó $2 \%$ del total gastado en todas las carenas. (Ver cuadro 13).

La última categoría de los proveedores de las carenas fue "Gastos administrativos”, que sumó $0,41 \%$ del total gastado en las mismas y se dividió (enumeradas por orden económico) en conducción de desertores, costas a funcionarios, impuesto ramo de guerra y apoderados. (Ver cuadro 14).

${ }^{56}$ J. Apolant, "Padrones olvidados de Montevideo", p. 71.

57 J. Apolant, "Padrones olvidados de Montevideo", p. 70.

${ }^{8}$ AGN, XIII-15-6-2.

${ }^{59}$ AGN, XIII-15-6-2. 
Cuadro 14: Carenado Fragatas-correo (1.767-1.802). Gastos administrativos. Dist. por subcategorías. Proporción del impacto de cada subcategoría en los gastos totales de las Carenas. Distri-

bución de los gastos por esferas económicas dinamizadas en relación con los gastos totales

\begin{tabular}{|l|r|r|r|r|r|r|}
\hline \multicolumn{10}{|c|}{$\begin{array}{c}\text { \% de las esferas económicas que los } \\
\text { gastos dinamizan }\end{array}$} \\
\hline Subcategorías & $\begin{array}{c}\text { Gastos en } \\
\text { pesos de 8 } \\
\text { reales }\end{array}$ & $\begin{array}{c}\text { \% dentro } \\
\text { de la } \\
\text { categoría }\end{array}$ & $\begin{array}{c}\text { \% sobre } \\
\text { valor } \\
\text { total } \\
\text { carena }\end{array}$ & Local & $\begin{array}{c}\text { Americana } \\
\text { extra } \\
\text { regional }\end{array}$ & $\begin{array}{c}\text { Extra } \\
\text { americana }\end{array}$ \\
\hline $\begin{array}{l}\text { Conducción de } \\
\text { desertores }\end{array}$ & 200,00 & 47,56 & 0,19 & 0,19 & 0,00 & 0,00 \\
\hline $\begin{array}{l}\text { Costas a } \\
\text { funcionarios }\end{array}$ & 112,00 & 26,64 & 0,11 & 0,11 & 0,00 & 0,00 \\
\hline $\begin{array}{l}\text { Impuesto Ramo de } \\
\text { guerra }\end{array}$ & 56,50 & 13,44 & 0,06 & 0,06 & 0,00 & 0,00 \\
\hline Apoderados & 52,00 & 12,36 & 0,05 & 0,05 & 0,00 & 0,00 \\
\hline Totales & 420,50 & 100,00 & 0,41 & 0,41 & 0,00 & 0,00 \\
\hline
\end{tabular}

Fuente: elaboración propia a partir de AGN, XIII-15-6-2.

A lo largo de estos 35 años analizados se pudo identificar que hubo servicios que por tratarse de un puerto fueron prioritarios, como los lancheros, pero que también en tierra se necesitaron diversos transportes relacionados con la logística portuaria, como son los viajes en carretas y/o en carretillas para descargar los pertrechos y llevarlos hasta el muelle o los almacenes de acopio o viceversa, lo que llevó a que haya una mayor especialización de este tipo de trabajo en la ciudad de Montevideo, ocasionados por la intensificación del tráfico.

No siempre se pudo identificar a los proveedores de transportes o de gastos administrativos, no obstante, pese a este impedimento, se han podido esbozar varias reflexiones sobre la condición socio-económica de éstos.

Hubo servicios en los cuales la participación económica de los individuos que los proveían fueron muy parejas en los montos cobrados, sin llegar a haber concentración por parte de unos pocos individuos. Fue el caso de los carretilleros; donde los dos mayores proveedores de esta subcategoría insumieron cada uno $28,63 \%$ del total general cobrado por estos transportistas, mientras que los siguientes proveedores identificados de este servicio tuvieron pequeñas participaciones económicas en cuanto al conjunto que oscilan entre $18,60 \%$ y $1,14 \%$. También hubo rubros en los que los trabajos estuvieron 
acaparados por diversos individuos y/o grupos de personas. Fue el caso de los carreteros, donde sólo un individuo abarcó el servicio cobrando 45,33\% del total. ${ }^{60}$

Diversos trabajadores de las Fragatas-correo figuran con su oficio declarado en los padrones de la época, como Fernando Requejo, quien también ya aparecía en el padrón de 1772-1773 revistando como carretero. ${ }^{61}$

Se pudieron identificar también tripulantes de embarcaciones que participan además del negocio del carenado y calafateado brindando servicios; como los casos de los proveedores de gastos administrativos Manuel Serrano, José de Guijano y Manuel García, integrantes de los barcos La Infanta, El Patagón y el Tucumán respectivamente, que se ocuparon de aprehender a los desertores y conducirlos al puerto. ${ }^{62}$

Hubo trabajadores que desarrollaron más de un servicio y/o proveyeron más de un producto en este carenado de las Fragatas-correo. Varios carreteros figuran también cobrando ellos mismos no sólo por sus viajes, sino también por los pertrechos que en sus transportes llevaban; como Pablo García y Fernando Requejo quienes además de cobrar por sus viajes en carretas, cobran por las enormes cantidades de piedras que transportaban. ${ }^{63}$

Se han identificado trabajadores de diversos oficios viviendo en la misma casa; el caso del carretero Fernando Requejo, viviendo como arrimado en casa de un pulpero que también era proveedor de insumos necesarios al carenado y calafateado. ${ }^{64}$ Esta característica de compartir la vivienda varios abastecedores, vuelve a repetirse, pues esto mismo fue observado en los proveedores de oficios, de estas Fragatas-correo y en los proveedores de comestibles, transportes, oficios y demás del Sitio a Colonia del Sacramento.

Hubo trabajadores de las Fragatas-correo que figuran con su oficio declarado en los padrones de la época, como Fernando Requejo, quien también ya aparecía en el padrón de 1772-1773 revistando como carretero. ${ }^{65}$

\footnotetext{
${ }^{60}$ AGN, XIII-15-6-2.

${ }^{61}$ J. Apolant, "Padrones olvidados de Montevideo", p. 70.

${ }^{62}$ AGN, XIII-15-6-2.

${ }^{63}$ AGN, XIII-15-6-2.

${ }^{64}$ J. Apolant, "Padrones olvidados de Montevideo", p. 70.

${ }^{65}$ J. Apolant, "Padrones olvidados de Montevideo", p. 70.
} 
Por último, en el aprovisionamiento de los servicios analizados en este trabajo, se han identificado proveedores con posibles lazos familiares entregando el mismo servicio; como los hermanos Requejo, estos carreteros que proveyeron más de la mitad de los viajes en carretas. ${ }^{66}$

Con respecto a los pagos, hubo transportistas que cobraron por jornal, otros por cada viaje, otros por el conjunto de sus servicios.

También hubo individuos que pese a ganar determinados contratos de asiento, esto no les impedía abastecer otros productos y dedicarse a más de un "frente" de trabajo a la vez (la Marina; la ciudad; los presos, los cuarteles, guardias y destacamentos, el tráfico de esclavos, entre otros). Se pudo observar que un proveedor como Francisco Antonio Maciel, al igual que varios de los asentistas de la Marina de Montevideo en la segunda mitad del siglo XVIII, tal vez por todo lo que la Corona les había brindado a partir de sus contratos y demás negocios que gracias a ellos pudieron lograr, fue defensor del poder real en Montevideo. ${ }^{67}$

Si bien los viajes regulares de las Fragatas-correo se cortan en 1802, siguió habiendo en el puerto de Montevideo muchos barcos del servicio real (estaba allí el apostadero naval en la región) que necesitaron estos diversos servicios para mantenerse en condiciones marineras. Si se recuerda que solamente se está considerando aquí a las Fragatas-correo y que desde mediados del siglo XVIII Montevideo centraliza cada vez más el tráfico ultramarino del Río de la Plata, se puede pensar que no le faltaría trabajo a todos estos proveedores y que posiblemente no tuvieran que dedicarse a otras labores que las asociadas con él.

\section{¿Cómo podrían agruparse los sectores sociales del complejo social laboral portuario rioplatense analizados?}

En la elite, por lo alto de la sociedad, se ubicarían los ya conocidos hacendados, los productores ganaderos, los grandes comerciantes, los altos funcionarios; y estos nuevos "empresarios multifacéticos-polivalentes" que reveló esta investigación, que eran actores bisagras, articuladores entre las necesidades de la Corona y la sociedad local en la concreción de la provisión de bienes y servicios. Eran actores sociales que articulaban provisión, producción y circulación; que tenían relaciones con el entramado institucional lo que les permitía ganar los contratos; actores a través de los cuales se redistribuía

${ }^{66}$ AGN, XIII-15-6-2.

${ }^{67}$ AGNU, ex AHM, caja No 245, carpeta 31. 
el gasto público. Eran aquellos asentistas generales, proveedores generales de una contienda, asentistas de rubros particulares (de víveres, de velas de sebo, de cerrajería y herrería, entre otros). Hubo asentistas que tuvieron establecimientos productivos propios en los cuales contaron con importantes cantidades de esclavos como fuerza laboral, varios de ellos especializados en la elaboración de los bizcochos. Otros contaron con una importante red de abastecedores para proveerse de todo lo que ellos no podían producir. Varios de estos asentistas desarrollaron múltiples y productivos negocios, muchos relacionados entre sí: asentistas, navieros, prestamistas, comerciantes, armadores de embarcaciones corsarias, saladeristas. A la vez que podían dedicarse a abastecer otros rubros además de a los barcos y a las tropas (a la ciudad, a los presos, los cuarteles, las guardias y destacamentos).

Integrando el sector medio estaban, por ejemplo, las "empresarias bizcocheras", presentes en todas las demandas: las embarcaciones del comercio y del servicio real, ya sea en puerto o navegando, en todos los circuitos extra-regionales terrestres y fluviales, carreteros de las rutas interiores y patrones de embarcaciones menores con destino a Paraguay, en la demanda de las tropas acantonadas en la región rioplatense y en tránsito, ya sea en paz o en conflicto. Además, integraban este sector los proveedores de otros alimentos como la carne salada o las miniestras y "asentistas subcontratistas", que integraban una segunda línea de abastecimiento y eran los individuos que, por más que en la legalidad no se podía hacer, subcontrataban determinado rubro, en particular el aprovisionamiento de bizcocho.

También formando parte del sector medio estaban los proveedores de oficios y profesiones que enriquecían el mercado de trabajo portuario del momento. Integrando el primer grupo se encontraban los herreros, carpinteros, armeros, latoneros, faroleros, estañadores, caldereros, toneleros, aserradores, albañiles, silleros, zapateros, pintores, cocedores de brea; todos oficios presentes en la demanda tanto de barcos como de tropas. Siendo parte de los profesionales estaban los prácticos de río, buzos, ingenieros, boticarios, cirujanos, capellanes, cocineros; también presentes en ambas demandas. Otros trabajadores incluidos en el sector medio eran los proveedores de servicios relacionados a la logística necesaria para cumplir la satisfacción de barcos y/o tropas; lancheros, carreteros, carretilleros, mandaderos, chasquis, estibadores-arrumadores y peones sin especialización. Abasteciendo a una sola de las demandas, como son las embarcaciones reales y las de la navegación privada, se ubican los calafates y marineros. Ambos eran trabajadores portuarios especializados, que el sostenido ritmo de crecimiento del complejo portuario 
María Emilia Sandrín

por la intensificación del tráfico ultramarino vio nacer en la región rioplatense. Proveyendo sólo a las tropas se evidenció la presencia de plateros.

Por último, pero no menos importantes, se posicionan en este sector medio aquellos pulperos, comerciantes diversificados, proveedores de insumos (ya sea relacionados entre sí, como velas y sebos; o con enorme y variada cantidad de productos abastecidos).

Se intentó llegar a lo más bajo de esas redes de relaciones, descubriendo a los individuos que están en los últimos escalones de esta pirámide, es decir, aquellos que son los productores y/o proveedores pequeños. Pero al no poder encontrar contratos de servicios, escrituras o documentos que permitan conocer cómo accedieron al trabajo, quién se los encargó; y sólo encontrar los recibos firmados por estos proveedores de determinado bien o servicio, se pudieron conocer los montos de las entregas, la periodicidad o no de las mismas, los pagos recibidos por los bienes y/o servicios provistos; en muchos casos sus nombres, en otros no; queda la duda de cómo serían los contratos, los arreglos para poder cumplir los diversas demandas. Hubo casos (especialmente en las bizcocheras con mayores participaciones económicas) en los que se pudo inferir la presencia del grupo familiar, trabajadores esclavos, indios conchabados, mujeres libres agregadas, en la realización de los trabajos. Ello se deduce dado los grandes volúmenes provistos en corto plazo y la presencia en el domicilio de esta enorme cantidad de gente viviendo en unidades habitacionales complejas. La mayoría de los proveedores son trabajadores independientes, libres que se especializan en el abastecimiento de determinado oficio, profesión o bien.

Este sector medio proveedor compartió características comunes. Podían compartir casa, ya sea entre varios trabajadores del mismo oficio, como de diversos oficios, pero todos abasteciendo para la misma demanda (ya sea para los barcos o para las tropas). Varios estaban emparentados entre sí (los “clanes” familiares de las bizcocheras, algunos carreteros y lancheros). Generalmente tenían una única especialización o dos similares (carpintero y aserrador, o farolero y latonero, herrero y carpintero). Muchos trabajadores figuraban en los padrones de la época con su oficio declarado, lo que ayuda a reforzar la idea de que ellos eran los que realizaban y cobraban el servicio o bien abastecido y por el cual firmaban el recibo de cobro (calafates, armeros, herreros, lancheros, carreteros). Algunos por su función o cargo se convirtieron en proveedores, eran los "proveedores-intermediarios" (capitanes, tenientes, maestros de los barcos, funcionarios como guarda almacenes, contadores). Otros abastecían tareas de su oficio y además proveían insumos para realizarlo (carpinteros entregando maderas, faroleros dando hierros, carreteros 
proveyendo piedras). En algunos rubros hubo abastecedores que monopolizaron las entregas de su especialidad (algunos herreros, carreteros), mientras que en la mayoría de las entregas era muy similar la participación económica entre varios proveedores; lo que permite verificar la dispersión social que los gastos generaron en la sociedad rioplatense, ya que eran muchas las personas involucradas en la satisfacción de ambas demandas (ya sea en forma alternada o simultánea). Se pudieron identificar distintas categorías de trabajadores, hubo oficiales, maestros, ayudantes, peones, aprendices; como así también la presencia de rubros subsidiarios de otros rubros mayores, fue el caso de los aserradores oficio surgido como complemento de la carpintería. También hubo oficios que surgieron con el tiempo y la demanda de esos servicios, el caso de los estañadores, que aparecieron casi a fines del siglo XVIII.

Respecto a la distribución por sexo de los trabajadores, en la concreción de lo necesario para el abastecimiento de las tropas, excepto el aprovisionamiento del bizcocho, que estaba dominado por las mujeres, los demás bienes y servicios fueron provistos por hombres. En cuanto a los servicios necesarios para mantener al barco en condiciones marineras, las tareas fueron realizadas exclusivamente por hombres.

Los pagos de los proveedores fueron variados, algunos eran por jornal, por producto terminado, por día, por mes, otros por el conjunto de sus servicios y/o bienes provistos.

Las demandas tanto de barcos como de tropas fueron cumplidas por este sector proveedor, ya que no se encontró a lo largo de los casos testigos analizados, ni una sola queja de no haber sido satisfechas las mismas; por lo que fueron muchas las personas que en el Río de la Plata aseguraron su subsistencia y por qué no su futuro, trabajando tanto en el complejo portuario como en el complejo productivo o de servicios. Lo que también ayudó a crear un cada vez más especializado y variado mercado de trabajo portuario regional. Mercado de trabajo que sigue reafirmando la unidad de la región rioplatense y la cuestión que el Río de la Plata no fue una frontera entre la Argentina "colonial" y el Uruguay "colonial" sino un espacio más de intercambio entre pobladores de uno y otro margen; ya que indistintamente los trabajos eran realizados en Buenos Aires o en Montevideo y continuamente iban trasladándose gente de un lado a otro del río, muchas veces con herramientas e insumos necesarios para llevar adelante su oficio o concretar la provisión de determinado bien (carpinteros con maderas, martillos, clavos; proveedores de leña con hachas y machetes). 
Si bien los dos casos testigo analizados fueron reveladores de una realidad económicamente significativa, no hay que olvidar que la totalidad de las demandas evidenciadas tanto para las embarcaciones de la navegación ultramarina como para las tropas a lo largo del siglo XVIII para la región Río de la Plata, podían darse en forma aislada, de a un grupo por vez, alternarse entre las dos o, lo que se dio en varias oportunidades, generarse ambas en simultáneo, lo que daría un impacto económico y una dinamización económica local mucho más importante que lo revelado en este artículo.

\section{Reflexiones finales}

A través del análisis de las diferentes fuentes seleccionadas, se pudo tener un acercamiento al sector social del mercado de trabajo portuario regional que vivía de la provisión de bienes y servicios para la navegación del servicio real y para el abasto de las tropas asentadas en el Río de la Plata, o en tránsito hacia otros destinos, en el siglo XVIII.

Se pudo llegar a individualizar, en la mayoría de los casos, a las personas que estaban detrás de cada uno de los aprovisionamientos de bienes y/o servicios necesarios para que estas embarcaciones estuvieran en condiciones marineras; con lo que permitió darles un nombre y un detalle a los individuos que realizaban determinado servicio y conocer también del mismo: quiénes eran los actores que los llevaban adelante, con quién vivían, si había relaciones familiares entre los trabajadores, qué oficios había en la región rioplatense de ese momento, cuánto les pagaban, qué representaba este valor en ese tiempo, qué insumos necesitaban para realizar sus tareas, de dónde venían los mismos, entre tantos datos que las fuentes brindaron.

De esta manera se pudo conocer a una gran cantidad de actores sociales cumpliendo las tareas de aprovisionamiento, formando un grupo diferenciado de individuos interconectados entre sí, integrados por distintos tipos de trabajadores que configuran en sí mismos equipos de trabajo donde se interrelacionan. Pudiendo ver desde los grandes comerciantes ricos a los sectores medios y bajos todo en un solo conjunto.

Se pudo apreciar una sociedad compleja, en movimiento e interrelación entre sus más diversos sectores que vivían del puerto y el aprovisionamiento de barcos y tropas; sectores sociales que no aparecen regularmente en las fuentes.

Se estableció que la demanda de bienes puede dividirse en dos grandes grupos. Los comestibles (principalmente los establecidos en la ración diaria reglamentaria, 
algunos con una importante y compleja cadena productiva) ${ }^{68}$ y los no comestibles (utensilios e insumos para los determinados "oficios portuarios" necesarios para el mantenimiento de las embarcaciones en condiciones marineras y para satisfacer los requerimientos de las tropas estables o en tránsito). ${ }^{69}$

Entre los servicios demandados se encuentran determinados oficios: calafates, estibadores/arrumadores, herreros, carpinteros, faroleros, caldereros, latoneros, estañadores, toneleros, armeros, aserradores, albañiles, silleros, zapateros, pintores, buzos, ingenieros, cocedores de brea, peones, entre otros; relacionados a la logística necesaria para un conflicto bélico o para mantener a una embarcación en "condiciones marineras": fletes de lancha, carreteros, carretilleros, chasquis, mandaderos, entre otros.

A lo largo del tiempo, las demandas de bienes y/o servicios por parte de barcos y tropas fueron constantes, tanto por el creciente número de embarcaciones la circulación ultramarina, como de expediciones en defensa de los territorios americanos; lo que evidenció trabajo constante para los individuos involucrados en la satisfacción de las demandas enumeradas. En el caso de que una decayera, el mismo sector proveedor seguía abasteciendo el mismo bien y/o servicio a la demanda alternativa. A su vez, además de constantes, sus trabajos fueron bien remunerados. Hay que recordar que ningún individuo ocupado en tareas vinculadas al puerto, a la construcción, a las panaderías solicitó informaciones de pobreza, y que no fueron considerados pobres los que cobraban un salario de 10 pesos mensuales o más; salario éste que hasta los trabajadores menos especializados analizados en este texto cobraban. ${ }^{70}$ Buenas remuneraciones para unos y ganancias para otros, también si se tiene en cuenta la bibliografía existente sobre los sectores populares en Europa del mismo período, donde se detallan hambrunas y terribles padecimientos de estos individuos. No está de más recordar el ejemplo del herrero que con pocos días de sus trabajos cubría el alquiler de una destacada casa del momento; o el carpintero que con poco más de la mitad de lo obtenido en 8 días de trabajo podía cubrir el alquiler anual de un cuarto donde vivir. Estos datos están en consonancia con los análisis de realizados por Johnson, quien sostiene que los oficios relacionados con la actividad portuaria, a lo largo

\footnotetext{
${ }^{68}$ Bizcocho, vino, tocino, miniestra de garbanzos o arroz, sal, carne salada, aceite, vinagre, queso. También se evidenciaron demandas de ajos, cebollas, tomates, jamones, lechugas, jamones, pasas de uva e higo, repollos, perdices, huevos, entre otros comestibles.

${ }^{69}$ Barriles, botijas, ollas, armas, hachas, martillos, calderos, faroles, vestimenta, telas, maderas, piedras, hierro, cobre, clavos, cueros, hilos, leña, entre tantos otros.

${ }^{70}$ Para más detalle sobre las informaciones de pobreza y los análisis de éstas ver Silvia Mallo, La sociedad rioplatense ante la justicia. La transición del siglo XVIII al XIX, La Plata, Publicaciones del Archivo Histórico de la Provincia de Buenos Aires, 2004.
} 
de la época colonial, fueron los mejores pagos de la ciudad..$^{71}$ También trabajos recientes sobre el mercado de trabajo en Montevideo en el siglo XVIII observan el importante premio por calificación que tenían los salarios de los trabajadores calificados tales como carpinteros y herreros. ${ }^{72}$

También, al analizar el seguimiento del origen económico de diversos insumos o servicios, las fuentes permitieron ver las distintas esferas económicas que la demanda de barcos fue estimulando. Si bien tanto el complejo productivo agropecuario como el área de servicios de la región rioplatense fueron altamente movilizados por las demandas de la navegación y de las tropas, generando una importante dinamización económica local, también resultaron estimuladas otras economías regionales americanas a través de la provisión de insumos necesarios que no se encontraban en la región. Con ello, el Río de la Plata se fue convirtiendo en una fuente de estímulo para producciones regionales que encontraron allí mercado.

El trabajo con las fuentes fiscales permitió además ver cómo la Corona, a través de los gastos que generaba el funcionamiento del aparato burocrático-militar, no fue solamente un agente explotador, sino que fue también generadora de recursos, dinamizadora de la economía local. Una peculiaridad de la región Río de la Plata, como se desprende de los escasos análisis sobre la fiscalidad, es que la corona gasta en ella mucho más de lo que recauda, con lo que la dinamización aludida deriva de la presión extractiva sobre otras sociedades. ${ }^{73}$

Si bien los resultados alcanzados fueron reveladores de una realidad económicamente significativa, no hay que olvidar que la totalidad de las demandas evidenciadas

\footnotetext{
${ }^{71}$ Lyman Johnson, Los talleres de la revolución. La Buenos Aires plebeya y el mundo del Atlántico, 1776-1810, Ciudad Autónoma de Buenos Aires, Prometeo Libros, 2013, p. 292, asegura que "un oficial calafateador que trabajaba 245 días en 1787, por ejemplo, ganaba más que un doctor en Derecho Canónico empleado por el Capítulo Catedral de Buenos Aires y más que la mayoría de los funcionarios empleados por el Tesoro Real”.

${ }^{72}$ María Inés Moraes y Florencia Thull, "Los salarios reales y el nivel de vida en una economía latinoamericana colonial: Montevideo entre 1760-1810", en Revista de Historia Económica - Journal of Iberian and Latin American Economic History, 36, 2018, pp. 185-213.

${ }^{73}$ Ver Samuel Amaral, "Las finanzas arcaicas: la atención del déficit en la Real Caja de Buenos Aires, 1789-1811", en Investigaciones y Ensayos, 60, 2011, pp. 381-436. Fernando Jumar \& María Emilia Sandrín, "El gasto público como dinamizador de la economía local. Río de la Plata en la primera mitad del siglo XVIII”, en Ernest Sánchez Santiró, (coord.), El gasto público en los imperios ibéricos. Siglo XVIII, México, Instituto Mora, 2015, pp. 205-272. Martín Wasserman, "Recursos fiscales para administrar el Imperio. La gestión de los ingresos al Ramo de Situados de Buenos Aires, 1766-1784", en Estudios del ISHIR, 19, 2017, pp. 82-115. M. Wasserman, "Gasto público y actividad económica en la Hispanoamérica de Antiguo Régimen: Buenos Aires en el siglo XVII. Una aproximación desde el Análisis de Redes Sociales”, en REDES, Revista Hispana para el Análisis de Redes Sociales, 29, 1, 2018, pp. 139-162. Roberto Schmit \& Martín Wasserman, "Una agenda abierta para los estudios históricos sobre la fiscalidad: Redistribución, negociación y deuda en el Río de la Plata durante un período de transiciones (1760-1820)", en Boletín del Instituto de Historia Argentina y Americana “Dr. Emilio Ravignani”, 49, 2018, pp. 145-175.
} 
tanto para las embarcaciones de la navegación ultramarina como para las tropas a lo largo del siglo XVIII para la región Río de la Plata, podían darse en forma aislada, de a un grupo por vez, alternarse entre las dos o, lo que se dio en varias oportunidades, generarse ambas en simultáneo, lo que daría un impacto económico y una dinamización económica local mucho más importante que lo revelado en este artículo; con la consiguiente oferta laboral para buena parte de la sociedad rioplatense.

\section{Bibliografía}

Archivo General de la Nación, Acuerdos del extinguido Cabildo de Buenos Aires, serie III, t. XI, 1933.

Amaral, Samuel, "Las finanzas arcaicas: la atención del déficit en la Real Caja de Buenos Aires, 1789-1811”, Investigaciones y Ensayos, 60, 2011, pp. 381-436.

Apolant, Juan Alejandro, Padrones olvidados de Montevideo del siglo XVIII. I y II, Montevideo, Imprenta Letras, Separata de Boletín Histórico, Estado Mayor del Ejército, 104-105 y 106-107, 1966.

Elias, Norbert, ¿Qu'est-ce que la sociologie?, París, L’Aube, 1991.

Hoberman, Louisa \& Socolow, Susan (comp.), Ciudades y sociedad en Latinoamérica colonial, Buenos Aires, Fondo de Cultura Económica, 1992.

Johnson, Lyman, Los talleres de la revolución. La Buenos Aires plebeya y el mundo del Atlántico, 1776-1810, Ciudad Autónoma de Buenos Aires, Prometeo Libros, 2013.

Jumar, Fernando, Nicolás Biangardi, José Bozzo, Sabrina Orlowski, Roberto Querzoli y María Emilia Sandrín, "El comercio ultramarino y la economía local en el complejo portuario rioplatense. Siglo XVIII”, en Anuario del IEHS, 21, 2006, pp. 235-254.

Jumar, Fernando, "El comercio ultramarino por el complejo portuario rioplatense y la economía regional, 1714-1778”, en Magallánica, Revista de Historia Moderna, 3, 5, 2016, pp. 166-259.

Jumar, Fernando, Le commerce atlantique au Río de la Plata, 1680-1778, 2da. ed. Aumentada, $1^{\mathrm{a}}$ ed. Electrónica, La Plata, UNLP, 2010, http://www.memoria.fahce. 
Maria Emilia Sandrín

unlp.edu.ar/tesis/te.364/te.364.pdf (consulta 10/02/2019).

Jumar, Fernando \& Nicolás Biangardi, “La conjunción entre espacio económico y territorialidad. Río de la Plata. Siglo XVIII”, en Richard Jorba \& Marta Bonaudo (coords.), Investigaciones regionales. Enfoques para la Historia, Siglos XVIII-XX, La Plata (Argentina), FaHCE-UNLP, 2014, pp. 75-91.

Jumar, Fernando \& María Emilia Sandrín, "El gasto público como dinamizador de la economía local. Río de la Plata en la primera mitad del siglo XVIII”, en Ernest Sánchez Santiró, (coord.). El gasto público en los imperios ibéricos. Siglo XVIII, México, Instituto Mora, 2015, pp. 205-272.

Jumar, Fernando, "La región Río de la Plata y su complejo portuario durante el Antiguo Régimen”, en Raúl Fradkin (dir.), Historia de la Provincia de Buenos Aires, Tomo II, Buenos Aires, Universidad Pedagógica de la Provincia de Buenos Aires, EDHASA, 2012, pp. 123-158.

Mallo, Silvia, La sociedad rioplatense ante la justicia. La transición del siglo XVIII al XIX, La Plata, Publicaciones del Archivo Histórico de la Provincia de Buenos Aires, 2004.

Moraes, María Inés y Florencia Thull, "Los salarios reales y el nivel de vida en una economía latinoamericana colonial: Montevideo entre 1760-1810”, en Revista de Historia Económica - Journal of Iberian and Latin American Economic History, 36, 2, 2018, pp. 185-213.

Sandrín, María Emilia, "El abasto y la provisión de bienes y servicios en el complejo portuario rioplatense. Siglo XVIII”, en Silvia Mallo \& Beatriz Moreyra (coord.), Miradas sobre la historia social en la Argentina en los comienzos del siglo XXI, Córdoba, Centro de Estudios Históricos, Prof. S. A, Segreti, La Plata, Centro de Estudios de Historia Americana Colonial, 2008, pp. 573-585.

Sandrín, María Emilia, "La actividad económica de los asentistas de víveres de la Marina de Montevideo, 1770-1810”, en América Latina en la Historia Económica, 21, 1, 2014a, pp. 92-114, http://www.scielo.org.mx/scielo.php?script=sci_arttext\&pi$\mathrm{d}=\mathrm{S} 1405-22532014000100004 \& \operatorname{lng}=\mathrm{es} \& \operatorname{lng}=\mathrm{es}$ (consulta 5/03/2019). 
Sandrín, María Emilia, "Análisis de las fuentes utilizadas y a utilizar para el estudio económico de los sectores sociales medios y/o bajos en el complejo portuario rioplatense. 1680-1810", en María Emilia Sandrín et al, Temas de Patrimonio cultural 30: Argentina de Puertos III (comp. por Marcelo Weissel), Buenos Aires, Comisión para la Preservación del Patrimonio Histórico-Cultural, Ministerio de Cultura-Gobierno de la Ciudad Autónoma de Buenos Aires, 2013, pp. 37-56.

Sandrín, María Emilia, Bizcocheras, lancheros y demás... Los estímulos económicos de la guerra para los sectores medios y bajos del complejo portuario rioplatense. 17351737, Saarbrücken, Editorial Académica Española, 2011.

Sandrín, María Emilia, "Los carpinteros, calafates, herreros, faroleros y demás trabajadores de las Fragatas-correo en Montevideo y su posible participación en el proceso emancipador”, en Naveg@mérica, 12, 2014, http://revistas.um.es/navegamerica (consulta 5/03/2019).

Sandrín, María Emilia, "La demanda de bienes y servicios para la Corona y la navegación ultramarina en el complejo portuario rioplatense y la dinamización de la economía regional. 1680-1810", Tesis de posgrado, Doctorado en Historia, Universidad Nacional de La Plata, Facultad de Humanidades y Ciencias de la Educación, 2016, http://www.memoria.fahce.unlp.edu.ar/tesis/te.1217/te.1217.pdf (consulta 5/03/2019).

Sandrín, María Emilia, "Las fuentes fiscales para abordar el complejo social-laboral portuario rioplatense: los libros de carenas. 1767-1802", en Revista Electrónica de Fuentes y Archivos "Prof. Carlos S. A. Segreti”, 8, 2017, pp. 156-174, http://www. refa.org.ar/file.php?tipo=Contenido\&id=177 (consulta 5/03/2019).

Sandrín, María Emilia, "La región Río de la Plata como articuladora de demandas que dinamizaron su economía en el largo siglo XVIII (1680-1810)", en Trabajos y Comunicaciones, 48, 2018, https://doi.org/10.24215/23468971eo71 (consulta 5/03/2019).

Sandrín, María Emilia, “¿Quién amasa la masa? Los proveedores de comestibles en el sitio a Colonia del Sacramento de 1735-1737", en Andes, 24, 1, 2013, http://www. scielo.org.ar/scielo.php?script=sci_arttext\&pid=S1668-80902013000100008\&l- 
María Emilia Sandrín

ng=es\&tlng=es. (consulta 5/03/2019).

Schmit, Roberto \& Wasserman, Martín L. E., "Una agenda abierta para los estudios históricos sobre la fiscalidad: Redistribución, negociación y deuda en el Río de la Plata durante un período de transiciones (1760-1820)", en Boletín del Instituto de Historia Argentina y Americana “Dr. Emilio Ravignani”, 49, 2018, pp. 145-175.

Torres Sánchez, Rafael, “Tejiendo una hacienda imperial: unir los manejos de la Real Hacienda de España y América en el reinado de Carlos III", en Michel Bertrand \& Zacarías Moutoukias (eds.), Changement institutionnel et fiscalité dans le monde hispanique (1750-1850), Toulouse, Université de Toulouse, 2014.

Wasserman, Martín L. E. "Recursos fiscales para administrar el Imperio. La gestión de los ingresos al Ramo de Situados de Buenos Aires, 1766-1784", en Estudios del ISHIR, 19, 2017, pp. 82-115.

Wasserman, Martín L. E. "Gasto público y actividad económica en la Hispanoamérica de Antiguo Régimen: Buenos Aires en el siglo XVII. Una aproximación desde el Análisis de Redes Sociales”, en REDES, Revista Hispana para el Análisis de Redes Sociales, 29, 1, 2018, pp. 139-162. 